Atmos. Chem. Phys., 10, 1329-1344, 2010

www.atmos-chem-phys.net/10/1329/2010/

(C) Author(s) 2010. This work is distributed under

the Creative Commons Attribution 3.0 License.

\title{
Aerosol hygroscopicity at high (99 to $100 \%)$ relative humidities
}

\author{
C. R. Ruehl ${ }^{1}$, P. Y. Chuang ${ }^{1}$, and A. Nenes ${ }^{2}$ \\ ${ }^{1}$ Earth \& Planetary Sciences, University of California, Santa Cruz, USA \\ ${ }^{2}$ Earth \& Atmospheric Sciences, Georgia Institute of Technology, Atlanta, USA
}

Received: 14 July 2009 - Published in Atmos. Chem. Phys. Discuss.: 24 July 2009

Revised: 28 December 2009 - Accepted: 15 January 2010 - Published: 5 February 2010

\begin{abstract}
The hygroscopicity of an aerosol strongly influences its effects on climate and, for smaller particles, atmospheric lifetime. While many aerosol hygroscopicity measurements have been made at lower relative humidities $(\mathrm{RH})$ and under cloud formation conditions $(\mathrm{RH}>100 \%)$, relatively few have been made at high RH (99 to 100\%), where the Kelvin (curvature) effect is comparable to the Raoult (solute) effect. We measured the size of droplets at high $\mathrm{RH}$ that had formed on particles composed of one of seven compounds with dry diameters between 0.1 and $0.5 \mu \mathrm{m}$. We report the hygroscopicity of these compounds using a parameterization of the Kelvin term, in addition to a standard parameterization $(\kappa)$ of the Raoult term. For inorganic compounds, hygroscopicity could reliably be predicted using water activity data (measured in macroscopic solutions) and assuming a surface tension of pure water. In contrast, most organics exhibited a slight to mild increase in hygroscopicity with droplet diameter. This trend was strongest for sodium dodecyl sulfate (SDS), the most surface-active compound studied. The results suggest that, for single-component aerosols at high $\mathrm{RH}$, partitioning of solute to the particle-air interface reduces particle hygroscopicity by reducing the bulk solute concentration. This partitioning effect is more important than the increase in hygroscopicity due to surface tension reduction. Furthermore, we found no evidence that micellization limits SDS activity in micron-sized solution droplets, as observed in macroscopic solutions. We conclude that while the high-RH hygroscopicity of inorganic compounds can be reliably predicted using readily available data, surface-activity parameters obtained from macroscopic solutions with organic solutes may be inappropriate for calculations involving micron-sized droplets.
\end{abstract}

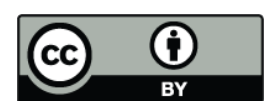

Correspondence to: C. R. Ruehl (crruehl@ucdavis.edu)

\section{Introduction}

Several mechanisms by which aerosols affect climate have been the subject of a great deal of recent study. These have broadly been classified as direct effects, in which particles interact directly with radiation, or indirect effects, in which variations in aerosol properties cause changes in cloud properties. The magnitude of both direct and indirect effects depends strongly on aerosol hygroscopicity, which we define as the amount of water absorbed by a particle with a given dry diameter at a given relative humidity (RH). Particles that readily absorb water at elevated $\mathrm{RH}$ have larger scattering cross-sectional areas than less hygroscopic particles, and are also more likely to act as cloud condensation nuclei (CCN), allowing them to indirectly affect climate. Accurate assessment of the effects of aerosols on climate therefore requires a detailed description of their hygroscopicities. In addition, wet deposition is the most efficient removal mechanism for particles with dry diameters $\left(D_{\text {dry }}\right)$ less than $1 \mu \mathrm{m}$ (Textor et al., 2006), and therefore hygroscopicity and CCN activity strongly influence particle lifetime and consequently total aerosol burden.

Aerosol hygroscopicity depends on two properties of the compounds present in a particle: their ability to lower the water activity $\left(a_{\mathrm{w}}\right)$ of an aqueous solution droplet, and their influence on the surface tension $(\sigma)$ of the droplet-air interface. Measurements of both $a_{\mathrm{w}}$ and $\sigma$, however, have typically been made using macroscopic solutions. (Henceforth we use the term "macroscopic" to describe these larger solutions with flat interfaces, in the same way that others have used the term "bulk." We reserve the term "bulk" for the portion of the droplet not at its surface.) Here, we explore the suitability and limitations of applying properties of macroscopic solutions to micron-sized drops.

It has been argued that the surface activity of aerosols influences climate by reducing droplet $\sigma$ below the value for pure water $\left(\sigma_{\mathrm{H}_{2} \mathrm{O}}=72.8 \mathrm{~mJ} \mathrm{~m}^{-2}\right.$ at $\left.25^{\circ} \mathrm{C}\right)$. This would

Published by Copernicus Publications on behalf of the European Geosciences Union. 
increase their hygroscopicity, resulting in higher cloud droplet concentrations and consequently greater cloud albedo (Facchini et al., 1999). Many calculations of aerosol particle hygroscopicity have used the reduced $\sigma$ measured in a macroscopic aqueous solutions (e.g., Facchini et al., 1999; Shulman et al., 1996; Lohmann and Leck, 2005; Rissman et al., 2004). Values of $\sigma$ obtained in macroscopic solutions have also been used in cloud parcel models (e.g., Ervens et al., 2005; Vanhanen et al., 2008), with results indicating an increase in cloud droplet concentrations of $\sim 10 \%$ relative to those assuming $\sigma_{\mathrm{H}_{2} \mathrm{O}}$. However, even when $\sigma$ is measured in relatively small macroscopic aqueous solution, the surface:volume ratio of the sample is much lower than found in microscopic droplets (Seidl and Hanel, 1983). For example, $\sigma$ has been measured in solution droplets with wet diameter $\left(D_{\text {wet }}\right) \sim 2 \mathrm{~mm}$, or a surface:volume ratio of $3000 \mathrm{~m}^{-1}$ (e.g., Shulman et al., 1996; Lima and Synovec, 1995; Varga et al., 2007; Dinar et al., 2007; Taraniuk et al., 2008), but the surface:volume ratio in $\sim 1 \mu \mathrm{m}$ droplets is greater than $10^{6} \mathrm{~m}^{-1}$. It is therefore possible that surface activities measured in macroscopic solutions are not germane to the CCN activity (i.e., hygroscopicity at the point of cloud droplet activation) of submicron particles.

There are several techniques that have been used to measure the hygroscopicity of droplets (as opposed to macroscopic solutions). Most involve droplets not with $D_{w e t} \sim 1 \mu \mathrm{m}$, but rather larger droplets with a smaller surface:volume ratio, measurements made at $\mathrm{RH}>99 \%$ recently using the LACIS instrument notwithstanding (Wex et al., 2005; Ziese et al., 2008; Niedermeier et al., 2008; Wex et al., 2009). For example, measurements of the hygroscopicity of larger droplets, typically with $D_{\text {wet }}$ between 20 and $40 \mu \mathrm{m}$, have been made using electrodynamic balances (e.g., Chan et al., 2008). High-resolution diameter measurements have also been made of droplets with $D_{\text {wet }} \sim 3$ to $7 \mu \mathrm{m}$ at high RH using optical tweezers (Hanford et al., 2008).

Recently, many studies have attempted to account for the high surface:volume ratio of microscopic droplets by explicitly modeling the adsorption of solute to the droplet-air interface and the resulting depletion of solute in the droplet bulk phase (i.e. the droplet interior away from the air interface). When this "partitioning effect" is taken into account, hygroscopicity can be reduced by one of two mechanisms: (1) if insufficient solute is available to completely cover the interface, $\sigma$ is reduced to a much lesser extent than in a macroscopic solution (Li et al., 1998; Sorjamaa et al., 2004; Topping et al., 2007), and (2) depletion of solute in the bulk droplet increases droplet water activity (Sorjamaa and Laaksonen, 2006). In both cases the modeled drop concentration is much closer to that obtained using $\sigma_{\mathrm{H}_{2} \mathrm{O}}$ (Kokkola et al., 2006). Although the partitioning effect may strongly limit the increase in hygroscopicity due to solute surface activity, some authors have argued that the CCN activity of organic material can only be accurately predicted if $\sigma$ is reduced to values similar to those observed in macroscopic solutions
(Dinar et al., 2006; Asa-Awuku et al., 2008; Broekhuizen et al., 2004). Others have found that prediction of the CCN activity of known surface-active compounds did not require any reduction in $\sigma$ (Abbatt et al., 2005; Sorjamaa et al., 2004). Also, recent work on organic aerosol particles produced from ozonolysis of $\alpha$-pinene has suggested that only minor reductions in $\sigma$ at activation are required to be consistent with hygroscopicity measured up to $\mathrm{RH}=99.6 \%$ (Wex et al., 2009).

In addition to the ability to partition and reduce surface tension, another property of many surface active compounds in macroscopic solutions is the tendency to form micelles (or more generally, aggregates) above the critical micelle concentration (CMC). The CMC can be determined in macroscopic solutions by slowly adding a surface-active compound; at the CMC, the activity coefficient of that compound in solution, which can be conceptualized as the fraction of "free" (i.e., not in a micelle) molecules in solution, will decrease sharply, and other solution properties related to micellization, such as turbidity, may begin to change. Tabazadeh (2005) used accepted CMC values for typical surface-active compounds in theoretical calculations to argue that micellization occurs in aerosol solution droplets containing surface-active compounds, which would lower their hygroscopicity both by limiting the amount of solute available to partition to the air-droplet interface and by raising the water activity in the droplet relative to a similar droplet in which no micellization occurs. However, as with measurements of the surface tension of macroscopic solutions, it is not clear that CMC values determined in such solutions are relevant to micron-sized droplets, with curved interfaces and much higher surface:volume ratios. In macroscopic solutions, the surface:volume ratio is small enough that the amount of solute at the interface can be neglected, and the CMC is determined by the tendency of free molecules to form micelles. However, in micron-sized droplets, the amount of solute at the interface might no longer be negligible, meaning that "free" surface active molecules can either partition to the interface or form micelles, and thus the CMC would be determined by both of these processes.

In this study, we measure the hygroscopicity of aerosol particles of known composition at high RH. We use droplets with $D_{\text {wet }} \sim 1 \mu \mathrm{m}$ because, as discussed below, such droplets are most sensitive to the Kelvin effect; consequently, most cloud droplets are approximately this size at the point of activation. Our primary purpose is to determine the extent to which hygroscopicity determined for droplets of this size differ from predictions based on properties of macroscopic solutions with much lower surface:volume ratios. Additionally, we address two general questions related to high-RH hygroscopicity. First, how well can aerosol hygroscopicity be represented with a single parameter, as has been done in numerous recent studies (e.g., Petters and Kreidenweis, 2007; Hudson and Da, 1996; Wex et al., 2007), for relatively wellstudied compounds at high values of RH (99.2 to $99.9 \%)$ ? 
Second, if the hygroscopicity of individual compounds does vary within the range of experimental conditions, which processes might be responsible?

\section{Theory}

\subsection{Sensitivity of $D_{\text {wet }}$ to the Raoult and Kelvin effects}

At elevated RH, atmospheric particles typically exist as solution droplets. Through condensation or evaporation of water, these droplets grow or shrink until they reach equilibrium with ambient RH. Hygroscopicity is the amount of water absorbed by a particle with a given dry diameter at a given $\mathrm{RH}$, and thus the more hygroscopic a particle, the greater its $D_{\text {wet }}$ at a given RH and $D_{\text {dry. }}$. Because hygroscopicity depends on water activity $\left(a_{\mathrm{w}}\right)$ and surface tension $(\sigma)$, these two variables appear in the Köhler equation, which relates the ambient RH in equilibrium with a droplet to various droplet properties:

$\mathrm{RH}=a_{\mathrm{w}} \exp \left(\frac{4 \sigma \overline{V_{\mathrm{w}}}}{R T D_{\text {wet }}}\right)$

Here $\overline{V_{\mathrm{w}}}$ is the molar volume of water (which approximates the dilute droplet), $R$ is the gas constant, and $T$ is temperature. $a_{\mathrm{w}}$ depends on the composition of the dry particle, as well as the molar ratio of solute to water in the droplet:

$a_{\mathrm{w}}=\exp \left(-\frac{\phi v n_{s}}{n_{\mathrm{w}}}\right)$

where $\phi$ is the osmotic coefficient, $v$ is the van't Hoff factor (the moles of soluble species per mole solute), and $n_{\mathrm{s}}$ and $n_{\mathrm{w}}$ are the moles of solute and water, respectively, in the droplet. The numerator of the exponential term in Eq. (2) is the number of osmoles in the solution droplet.

The Raoult effect is defined as the influence of the number of osmoles (for which we will use $\phi$ as a proxy) on hygroscopicity, while the Kelvin effect is defined as the effect of $\sigma$ on hygroscopicity. The sensitivity of $D_{\text {wet }}$ to these variables can be defined as the ratio of the resulting fractional change in $D_{\text {wet }}$ to a small fractional change in either variable, e.g.:

$\frac{d \widetilde{D}_{\mathrm{wet}}}{d \widetilde{\phi}}=\frac{d D_{\mathrm{wet}}}{d \phi} \times \frac{\phi_{\mathrm{o}}}{D_{\text {wet }, \mathrm{o}}}$

at some reference wet diameter ( $\left.D_{\text {wet,o }}\right)$ with a corresponding osmotic coefficient $\left(\phi_{\mathrm{o}}\right)$. The sensitivity of $D_{\text {wet }}$ to $\sigma$ can be defined analogously. To calculate these sensitivities, we assume a dry particle made of a single component with a molar volume equal to a model surfactant (sodium dodecyl sulfate, or SDS). Then Eqs. (1) and (2) can be used to solve for $\frac{d \widetilde{D}_{\text {wet }}}{d \widetilde{\phi}}$ and $\frac{d \widetilde{D}_{\text {wet }}}{d \widetilde{\sigma}}$. The sensitivity of $D_{\text {wet }}$ to $\phi$ increases gradually with $\mathrm{RH}$, reaching $20 \%$ around $\mathrm{RH}=90 \%$ and $30 \%$ around $\mathrm{RH}=98 \%$ (Fig. 1a). In contrast, the sensitivity of $D_{\text {wet }}$ to $\sigma$ is a much stronger function of
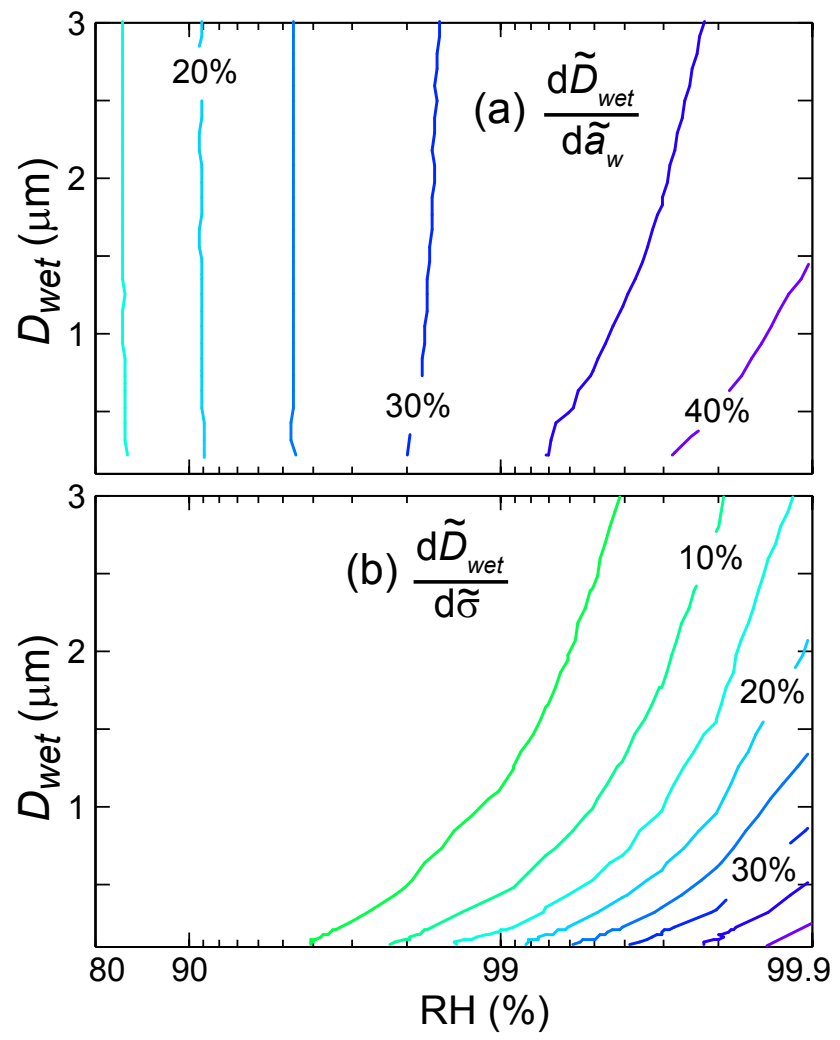

Fig. 1. Sensitivity of $D_{\text {wet }}$ to changes in (a) water activity and (b) surface tension. Contour interval is $5 \%$.

both $D_{\text {wet }}$ and RH (Fig. 1b), and only reaches $20 \%$ when $\mathrm{RH} \gtrsim 99 \%$ and $D_{\text {wet }} \lesssim 2 \mu \mathrm{m}$. This is because the magnitude of the Kelvin effect approaches that of the Raoult effect as $\mathrm{RH} \rightarrow 100 \%$ (Lewis, 2008), and also due to the greater curvature of smaller droplets which increases the importance of the Kelvin effect. Similar conclusions were reached by Wex et al. (2008), who found that the sensitivity of $D_{\text {wet }}$ to $\sigma$ is negligible when $\mathrm{RH}<95 \%$, but increases sharply as RH approaches $100 \%$. Wex et al. (2008) also found that the sensitivity of $D_{\text {wet }}$ to the number of osmoles was greater for more hygroscopic particles; in our analysis as well the sensitivity of $D_{\text {wet }}$ to $\phi$ increased when we assumed the dry particle was composed of ammonium sulfate instead of SDS.

\subsection{Parametrization of aerosol hygroscopicity}

Although hygroscopicity is influenced by several physicochemical properties (e.g. molar volume, aqueous solution activity, surface tension), it has been represented for both ambient and lab-generated particles by a single parameter based on Eq. (1), defined similarly but not identically in several studies (e.g., Fitzgerald et al., 1982; Hudson and Da, 1996; Wex et al., 2007; Petters and Kreidenweis, 2007). Because hygroscopicity is more sensitive to the Raoult term than the Kelvin term for all but the smallest particles at the highest RH 
(Fig. 1), most proposed parametrizations are defined through their effect on the water activity $\left(a_{\mathrm{w}}\right)$. To facilitate comparison with other studies, we employ the commonly-used $\kappa$ formulation of Petters and Kreidenweis (2007), in which $\kappa$ relates $a_{\mathrm{w}}$ to the ratio of the volume of water $\left(V_{\mathrm{w}}\right)$ to volume of solute $\left(V_{\mathrm{s}}\right)$ in the droplet:

$\kappa=\frac{V_{\mathrm{w}}}{V_{\mathrm{s}}}\left(\frac{1}{a_{\mathrm{w}}}-1\right)$

In this formulation, $\kappa$ ranges from zero for an insoluble but wettable substance to a maximum of approximately 1.3 for sodium chloride. Trends in hygroscopicity with RH, which are emphasized in this study, should be similar no matter which parametrization of the Raoult term is used. We wish to incorporate all factors influencing hygroscopicity into a single parameter, without introducing additional parameters such as those in the Szyszkowski equation (Szyskowski, 1908 ) which is typically used to express $\sigma$ as a function of solute concentration. Our approach is therefore to assume $\sigma=\sigma_{\mathrm{H}_{2} \mathrm{O}}$, and we therefore insert the definition of $\kappa$ (Eq. 4) into the Köhler equation:

$\mathrm{RH}=\frac{D_{\text {wet }}^{3}-D_{\text {dry }}^{3}}{D_{\text {wet }}^{3}-D_{\text {dry }}^{3}(1-\kappa)} \exp \left(\frac{4 \sigma_{\mathrm{H}_{2} \mathrm{O}} \overline{V_{\mathrm{w}}}}{R T D_{\text {wet }}}\right)$

Our experiments involve measuring $D_{\text {wet }}$ at selected values of RH and $D_{\text {dry }}$. Equation (5) is used to transform $D_{\text {wet }}$ into $\kappa$. If the actual surface tension of the droplet is lower than $\sigma_{\mathrm{H}_{2} \mathrm{O}}, \kappa$ will be overestimated because $D_{\text {wet }}$, and therefore $V_{\mathrm{w}}$ (Eq. 4), will be larger than that of an equivalent droplet with $\sigma=\sigma_{\mathrm{H}_{2} \mathrm{O}}$.

Any variation in hygroscopicity, regardless of the cause, will be reflected in $\kappa$. For example, an increase in $\kappa$ with RH could be caused by either non-ideal behavior at higher concentrations (i.e., lower RH), or by a surface tension lower than that assumed in the $\kappa$ formulation (i.e., $\sigma_{\mathrm{H}_{2} \mathrm{O}}$ ). Essentially, the issue is that RH and $D_{\text {dry }}$ are controlled, and only one experimental variable, $D_{\text {wet }}$, is measured. It is therefore impossible to cleanly separate the multiple effects (e.g., osmolality and surface tension) affecting hygroscopicity. Nevertheless, we attempt to distinguish between solute and surface effects by defining an alternative hygroscopicity parameter, $\delta$. First, we take the linear regression of $\kappa$ onto RH, and assume that this captures any variation in solution nonideality that occurs over this $\mathrm{RH}$ range. We then incorporate this variation into the definition of $\delta$, described below. $\delta$ can thus be thought of as a hygroscopicity parameter that has been detrended with respect to RH, and will be used to look for trends in hygroscopicity with $D_{\text {wet }}$ which are likely caused by surface effects. Still, while linear regression of any single hygroscopicity parameter onto RH or $D_{\text {wet }}$ has the advantage of simplicity and an ability to determine if trends are statistically significant, caution must be applied when interpreting results, and multiple causes of any observed trends must be considered.
As can be seen in Eq. (5), $\kappa$ is a parametrization of the Raoult term in Eq. (1). To express observed $D_{\text {wet }}$ values as $\kappa$ (when $D_{\text {dry }}$ and RH are known), a surface tension must be assumed. We also parametrize the the Kelvin term by defining a length scale (Lewis, 2008):

$\delta=\frac{4 \sigma \overline{V_{\mathrm{w}}}}{R T}$

and substitute into the Köhler equation:

$\mathrm{RH}=\exp \left(-\frac{\phi \nu n_{\mathrm{s}}}{n_{\mathrm{w}}}\right) \exp \left(\frac{\delta}{D_{\text {wet }}}\right)$

We use Eq. (7) to calculate $\delta$ given experimentallydetermined $D_{\text {wet }}, D_{\text {dry }}$, and RH, just as Eq. (5) is used to derive $\kappa$ from these same quantities. As before, we must make an assumption regarding the term that is not parameterized, in this case the Raoult term. Specifically, we must assume the number of osmoles $\left(\phi v n_{\mathrm{S}}\right)$ in the droplet (given particle composition and $D_{\text {dry }}$ ). We use the relationship between $\kappa$ and RH discussed above to determine this quantity. Because any trend in hygroscopicity with RH has been removed from $\delta$, it much more likely that any observed trend in $\delta$ with $D_{\text {wet }}$ is due to changes in surface activity, as opposed to non-ideality. For an ideal droplet at $25^{\circ} \mathrm{C}$ with the surface tension of pure water, $\delta=2.1 \mathrm{~nm}$, and because $\delta \propto \sigma$, as hygroscopicity increases, derived $\delta$ decreases.

\subsection{Predicted values of $\kappa$}

Figure 2 shows theoretical predictions of derived $\kappa$ for different solute and RH conditions. Combining Eqs. (2) and (4), it can be shown that, if $\mathrm{RH} \simeq 100 \%$,

$\kappa \simeq v_{s} \phi \bar{V}_{\mathrm{w}} / \overline{V_{\mathrm{s}}}$

For an ideal, non-surface active solute, $\kappa$ is constant throughout the range of RH examined in this study (Fig. 2, black curves). For non-ideal, non-surface active solutes, $\kappa$ is proportional to $\phi$ (Fig. 2a and b, blue curves). For surfaceactive solutes, $\sigma$ is reduced, which in turn raises derived $\kappa$ an amount that increases with increasing RH (Fig. 2a and b, red curves). While this increase in $\kappa$ is sensitive to $\mathrm{RH}$, it is reasonably insensitive to $D_{\text {dry }}$ (Fig. 2a). Not all dependence on $D_{\text {dry }}$ is removed, however, unless the surface tension of the droplet equals the assumed surface tension used in Eq. (5). Note that the sensitivity of $\kappa$ to $D_{\text {dry }}$ is much greater if one looks for a trend in $\kappa$ with $D_{\text {wet }}$ (Fig. 2b).

We compare our experimental values of $\kappa$ to theoretical predictions. Calculation of theoretical values for $\kappa$ amounts to describing $a_{\mathrm{w}}$ as a function of $D_{\mathrm{dry}}$ and RH. We use Eq. (2), which requires assumptions for $\phi$ and $v$, as well as calculations for $n_{\mathrm{s}}$ and $n_{\mathrm{w}} . n_{\mathrm{s}}$ depends on the size of the dry particle:

$n_{\mathrm{s}}=\frac{\pi D_{\mathrm{dry}}^{3}}{6 \overline{V_{\mathrm{s}}}}$ 
where $n_{\mathrm{w}}$ depends on $D_{\text {wet }}$ after the volume of solute has been subtracted:

$n_{\mathrm{w}}=\frac{\pi\left(D_{\mathrm{wet}}^{3}-D_{\text {dry }}^{3}\right)}{6 \overline{V_{\mathrm{w}}}}$

For most common solutes, including the ones examined here, $\phi$ as a function of $\frac{n_{\mathrm{s}}}{n_{\mathrm{w}}}$ is well-known based on measurements of the water activity of macroscopic solutions, even at the upper end of the range of $a_{\mathrm{w}}$ that is the focus of this study. For sodium chloride, ammonium sulfate, and malonic acid, we used the E-AIM water activity model to determine $\phi$ (Clegg et al., 1998, 2001), and use Eqs. (2) and (4) to calculate $\kappa$ as a function of $\mathrm{RH}$. This model is based on experimental water activities measured in macroscopic solutions, and we compare our experimental results to it to determine how valid it may be for microscopic droplets. For sucrose and glucose, we also compared our data to predictions based on macroscopic experimental values (Clegg et al., 2001; Stokes and Robinson, 1966), which indicate that $\phi>1$ for these sugars.

\subsection{Predicted values of $\delta$}

As discussed previously, we parametrize the Kelvin term in the Köhler equation to examine trends in hygroscopicity with droplet diameter $\left(D_{\text {wet }}\right)$ using the length scale $\delta$, which is proportional to surface tension $(\sigma)$ and defined in Eq. (7). This is analogous to the use of Eq. (5) to parametrize the Raoult term as $\kappa$. We assume a relationship between $\phi$ (again, a proxy for osmoles) and RH based on the regression of $\kappa$ onto RH, and so this dependence of hygroscopicity on $\mathrm{RH}$ has been removed from $\delta$. By accounting for any measured RH-dependence of the Raoult term, we can then attribute remaining variability to the Kelvin term, which will show up as variation in $\delta$. This is the primary motivation for using the $\delta$ parameterization. If the surface tension of a solution droplet is lower than that of pure water, but the partitioning effect is negligible, the observed value of $\delta$ will be lower than that of an ideal solution droplet with $\sigma=\sigma_{\mathrm{H}_{2} \mathrm{O}}$ (Fig. 2c, red curves). $\delta$ is also sensitive to the assumed value of $\phi$; (Fig. 2c, blue curves).

The reduction of $\sigma$ in macroscopic aqueous surfactant solutions is typically limited by formation of micelles above a certain certain bulk solute concentration. For SDS, this socalled Critical Micelle Concentration (CMC) is $8.2 \mathrm{~mol} \mathrm{~m}^{3}$, at which point $\sigma$ is reduced to $\sim 40 \mathrm{~mJ} \mathrm{~m}^{2}$. The range of SDS concentrations observed in this study is 110 to $340 \mathrm{~mol} \mathrm{~m}^{-3}$, the entirety of which is more than 10 times greater than the CMC, suggesting that for all SDS solution droplets, excess SDS will be present to reduce $\sigma$ to whatever minimum value corresponds to saturation of the interface by SDS.

The partitioning effect can be accounted for by assuming that the solute is distributed between the bulk solution and the surface (Sorjamaa et al., 2004; Li et al., 1998):

$n_{\mathrm{s}}^{\text {tot }}=n_{\mathrm{s}}^{\text {bulk }}+n_{\mathrm{s}}^{\text {surf }}$
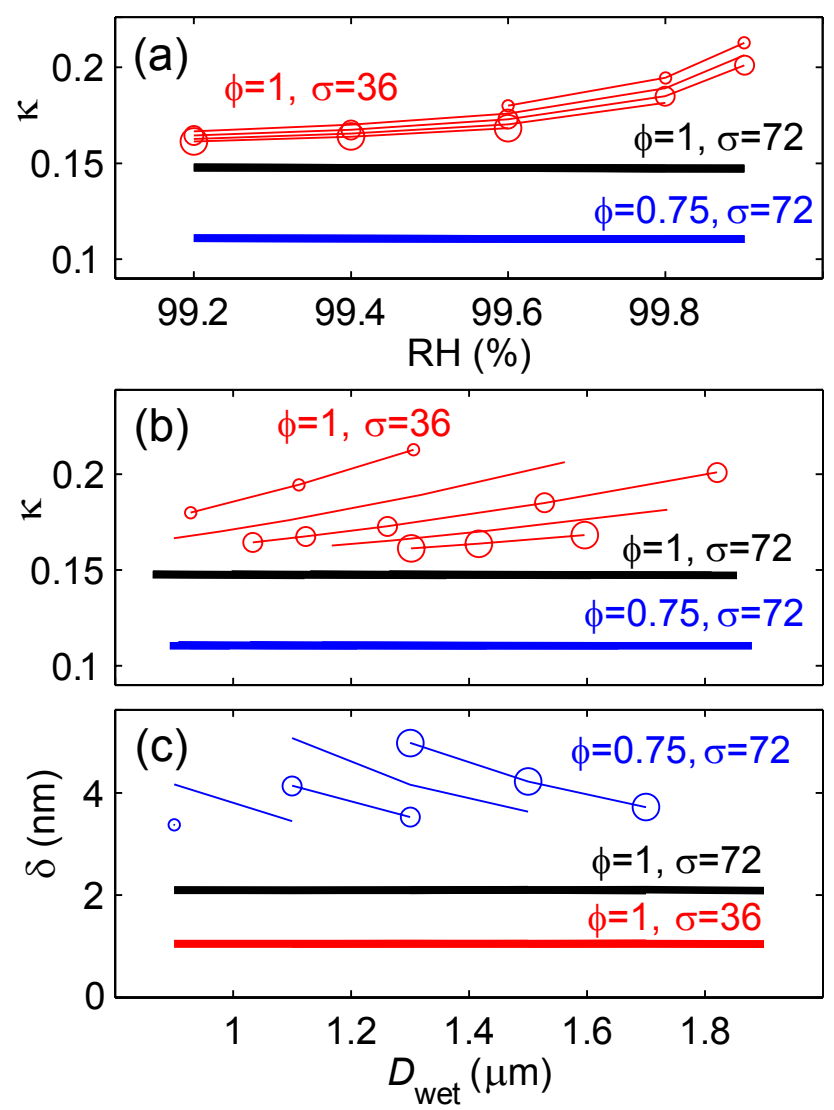

Fig. 2. Theoretical variation of $\kappa$ with both (a) RH and (b) $D_{\text {wet }}$, and of (c) $\delta$ with $D_{\text {wet }}$. Black curves are for ideal SDS solution droplets with $\sigma_{\mathrm{H}_{2} \mathrm{O}}$, red curves assume $\sigma$ is reduced by half, and blue curves assume $\phi=0.75$. $D_{\text {dry }}$ is indicated by symbol size.

Under the SDS concentrations observed here (110 to $340 \mathrm{~mol} \mathrm{~m}^{-3}$ ), we assume that the surface is saturated, and therefore:

$n_{\mathrm{s}}^{\text {surf }}=\pi D_{\mathrm{wet}}^{2} \Gamma$

SDS has a cross-sectional area of $\sim 30 \AA^{2}$ per molecule (Prosser and Franses, 2001), and therefore a monolayer of SDS is equivalent to an excess surface concentration $(\Gamma)$ of $6 \times 10^{-6} \mathrm{~mol} \mathrm{~m}^{-2}$. Given a value of $D_{\text {dry }}, \Gamma$, and $\mathrm{RH}$, Eq. (12) can be solved iteratively for $n_{\mathrm{s}}^{\text {surf }}$ and $D_{\text {wet }}$. This model of the SDS solution droplet with a complete coating of solute at the droplet-air interface is similar to the "inverted micelle" model of solution droplets with organic solutes that has been previously described (Gill et al., 1983; Ellison et al., 1999), and for which some observational evidence has been obtained (e.g., Husar and Shu, 1975; Tervahattu et al., 2002; Russell et al., 2002). However, this blurs the distinction between soluble (e.g., SDS) and insoluble (e.g., fatty acids) surfactants (Moroi et al., 2004). For a soluble surfactant, the excess surface concentration is not expected to reside exclusively at the interface (e.g., purely in a self-assembled monolayer), but rather as a concentration gradient between 
the bulk and surface phases. As a consequence, $\Gamma$ may be greater than a monolayer equivalent $\left(\sim 6 \times 10^{-6}\right.$ for SDS $)$. To the extent that the partitioning effect does deplete solute from the bulk phase, hygroscopicity will decrease and $\delta$ will therefore be greater.

\subsection{Specific questions addressed by this study}

We compare observed hygroscopicity (as expressed by the parameters $\kappa$ and $\delta$ ) to values calculated under different assumptions regarding the terms $a_{\mathrm{w}}$ (i.e., the Raoult effect) and $\sigma$ (i.e., the Kelvin effect) in Eq. (1). We use these observations to answer the following specific questions:

1. How well do $a_{\mathrm{w}}$ measurements made of macroscopic solutions describe the high-RH hygroscopicity of micron-sized droplets?

2. Does the micellization of SDS limit its hygroscopicity?

3. How well do $\sigma$ measurements made using macroscopic solutions describe the high-RH hygroscopicity of micron-sized droplets?

4. And finally, for our model surface-active compound (SDS), does partitioning of solute to the droplet-air interface and the resulting depletion in the bulk droplet (i.e., the partitioning effect) need to be taken into account to accurately predict hygroscopic growth?

\section{Experimental}

Particles of known composition were generated by atomizing aqueous solutions with a high-pressure nitrogen jet. After atomization, particles flowed through two diffusion driers, which lowered the RH of the flow to below $10 \%$. After drying, particles entered a differential mobility analyzer (DMA, manufactured by TSI), which selected particles of a certain electrical mobility. While this quasi-monodisperse population was primarily made up of singly-charged particles with diameters $\left(D_{\text {dry }}\right)$ between 0.2 and $0.5 \mu \mathrm{m}$, it always included some larger, multiply-charged particles of equal mobility. The sheath and sample flow rate in the DMA were 2 and $0.2 \mathrm{~L} \mathrm{~min}^{-1}$, respectively. The quasi-monodisperse flow was split, with half going to a condensation nucleus counter and half going to a continuous-flow thermal gradient column (CFTGC). A dynamic shape correction factor $(\chi)$ of 1.08 was used for $\mathrm{NaCl}$ aerosol, 1.04 for ammonium sulfate (AS) aerosol, and no shape correction was made $(\chi=1)$ for any of the organic aerosol tested (Zelenyuk et al., 2006; Krämer et al., 2000).

Flow in the CFTGC proceeds through $1 \mathrm{~m}$ of stainless steel tubing with an ID of $0.022 \mathrm{~m}$. Temperature is controlled at four locations along the tube with high-precision thermistors and thermo-electric coolers. The inside wall of the tubing is coated with filter paper, which is saturated with water before use. In previous experiments, the CFTGC has been operated in "CCN" mode, in which a positive temperature gradient $(\Delta T)$ was imposed in the direction of the flow (Ruehl et al., 2008, 2009). Water vapor diffuses more quickly from the inner wall to the centerline than does the bulk gas (due to its lower molecular mass), causing a supersaturation $(\mathrm{RH}>100 \%)$ along the centerline. This technique of producing a supersaturation was described in Roberts and Nenes (2005). In the experiments of this study, the CFTGC was operated in "high-RH" mode: a negative $\Delta T$ in the direction of flow was applied, and water vapor diffused more rapidly from the centerline to the inner walls, lowering the $\mathrm{RH}$ along the centerline below unity, to somewhere in the range of 99.2 to $99.9 \%$ (depending on $\Delta T$ ). The overall flow rate in the column was $0.94 \mathrm{~L} \mathrm{~min}^{-1}$, of which $0.1 \mathrm{~L} \mathrm{~min}^{-1}$ was the quasi-monodisperse flow along the centerline, and the remainder was a humidified, particle-free sheath flow.

Before exiting the CFTGC, the diameter and velocity of droplets along the centerline was measured with a phase Doppler interferometer (PDI) manufactured by Artium Technologies, Inc. (Bachalo, 1980; Bachalo and Houser, 1984). Diameters were binned at $0.1 \mu \mathrm{m}$ intervals. To get a sense of the precision of these measurements, we measured $D_{\text {wet }}$ spectra at $\Delta T=1 \mathrm{~K}$ for droplets formed on dry $\mathrm{NaCl}$ particles. The mobility diameter of the $\mathrm{NaCl}$ particles was increased from $100 \mathrm{~nm}$ to $400 \mathrm{~nm}$ at $10 \mathrm{~nm}$ intervals (Fig. 3). Larger droplets formed on larger, multiply-charged particles were resolved in most spectra. A bimodal (both normallydistributed) fit was found for each spectra, and the smaller $D_{\text {wet }}$ mode (which was always the more numerous) was assumed to be the singly-changed mode. The standard deviation of this mode ranged from 0.10 to $0.42 \mu \mathrm{m}$, or from 7 to $22 \%$ of the mean. Replicate measurements of $D_{\text {wet }}$ standard deviation were made at several $D_{\text {dry }}$, and ranged from 0.03 to $0.30 \mu \mathrm{m}$ (3 to $15 \%$ of the mean). However, when restricted to $D_{\text {wet }}<2.0 \mu \mathrm{m}$, which includes all droplets in this study except those formed on the largest $\mathrm{NaCl}$ and AS particles, standard deviations of replicate measurements ranged from 0.03 to $0.13 \mu \mathrm{m}$ ( 3 to $9 \%$ of the mean).

$\mathrm{RH}$ in the CFTGC was calibrated with $\mathrm{NaCl}$ particles, which required an assumption of $\kappa$. Based on the E-AIM model (Clegg et al., 1998, 2001), we assumed $\mathrm{NaCl} \kappa$ increased slightly over the relevant $\mathrm{RH}$ range, from 1.24 to 1.27 , and then used Eq. (5) to relate $\mathrm{RH}$ to $D_{\text {wet }}$ of $\mathrm{NaCl}$ solution droplets at a given $\Delta T$. We found a linear relationship between RH and $\Delta T$, but saw slight variation in absolute RH $(\sim 0.05 \%)$ at the same $\Delta T$ on different days (Fig. 4). Therefore instead of utilizing the linear regression of RH onto $\Delta T$, for all compounds besides $\mathrm{NaCl}$ we transformed $D_{\text {wet }}$ into $\kappa$ using the $\mathrm{NaCl}$-calibrated $\mathrm{RH}$ for the individual day of the measurements. It should be mentioned that RH is very sensitive to $T$, such that an increase in $T$ of only $0.015 \mathrm{~K}$ would result in a decrease in $\mathrm{RH}$ of $0.1 \%$. This calibration therefore suggests that the temperature in the view volume was stable to within $\sim 0.01 \mathrm{~K}$, which is approximately the precision of the thermistors. 


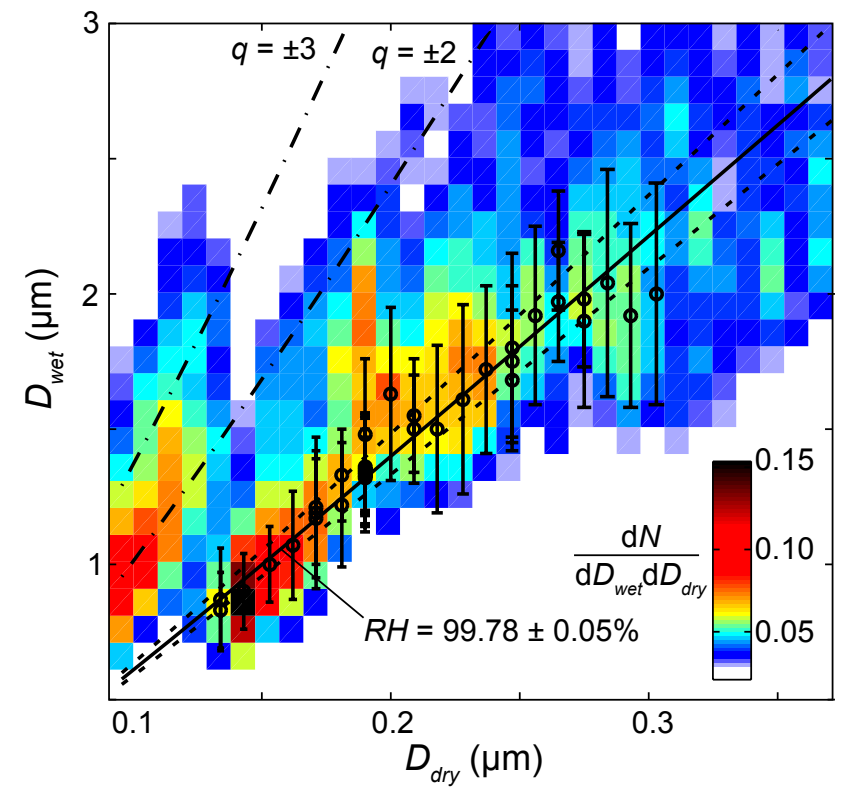

Fig. 3. $D_{\text {wet }}$ spectra (color), vs. $D_{\text {dry }}$ of $\mathrm{NaCl}$ particles. Includes $D_{\text {wet }}$ fit peaks (circles) and standard deviations (error bars) used to determine RH, along with a solid line for the best fit RH, dotted lines indicating the precision of the RH calculation, and dash-dot lines representing multiply-charged particles selected by the DMA.

Table 1. High-RH hygroscopicity ( $\kappa_{\mathrm{obs}}$ ) of the $\mathrm{NaCl}$ reference and six other compounds. Also $\kappa_{\text {ideal }}$, the theoretical value at $\mathrm{RH}=100 \%$ assuming an ideal solution, infinite solubility, and either complete dissociation ( $\mathrm{NaCl}, \mathrm{AS}$, and SDS) or no dissociation (malonic and adipic acids, glucose, and sucrose). Also listed are the slopes $(\mathrm{m})$ and $p$-values for linear regressions of $\kappa$ onto RH. $p$-values under $5 \%$ are in boldface.

\begin{tabular}{llllrr}
\hline & $\kappa_{\text {obs }}$ & $\kappa_{\text {ideal }}$ & $n$ & $\begin{array}{r}m \\
{\left[\% \%^{-1}\right]}\end{array}$ & $p$ \\
\hline $\mathrm{NaCl}$ & $1.27^{*} \pm 0.11$ & 1.33 & 77 & -1.2 & 0.84 \\
$\mathrm{AS}$ & $0.572 \pm 0.074$ & 0.72 & 54 & 20 & 0.068 \\
malonic acid & $0.291 \pm 0.057$ & 0.28 & 35 & 46 & $\mathbf{0 . 0 0 9}$ \\
adipic acid & $0.185 \pm 0.040$ & 0.168 & 13 & 100 & 0.050 \\
glucose & $0.165 \pm 0.033$ & 0.154 & 20 & 63 & 0.13 \\
SDS & $0.134 \pm 0.029$ & 0.147 & 53 & 2.72 & 0.86 \\
sucrose & $0.112 \pm 0.020$ & 0.084 & 27 & -54 & $\mathbf{0 . 0 2 8}$ \\
\hline
\end{tabular}

* This value was fixed in the RH calibration.

\section{Results and discussion}

\subsection{Overall results}

As expected, the high-RH hygroscopicity, expressed as $\kappa$, of both inorganic compounds was greater than that of any of the five organic compounds (Table 1). $\mathrm{NaCl}$ was the most hygroscopic compound studied $(\kappa=1.27 \pm 0.11$, with the mean value fixed by the CFTGC calibration), followed by

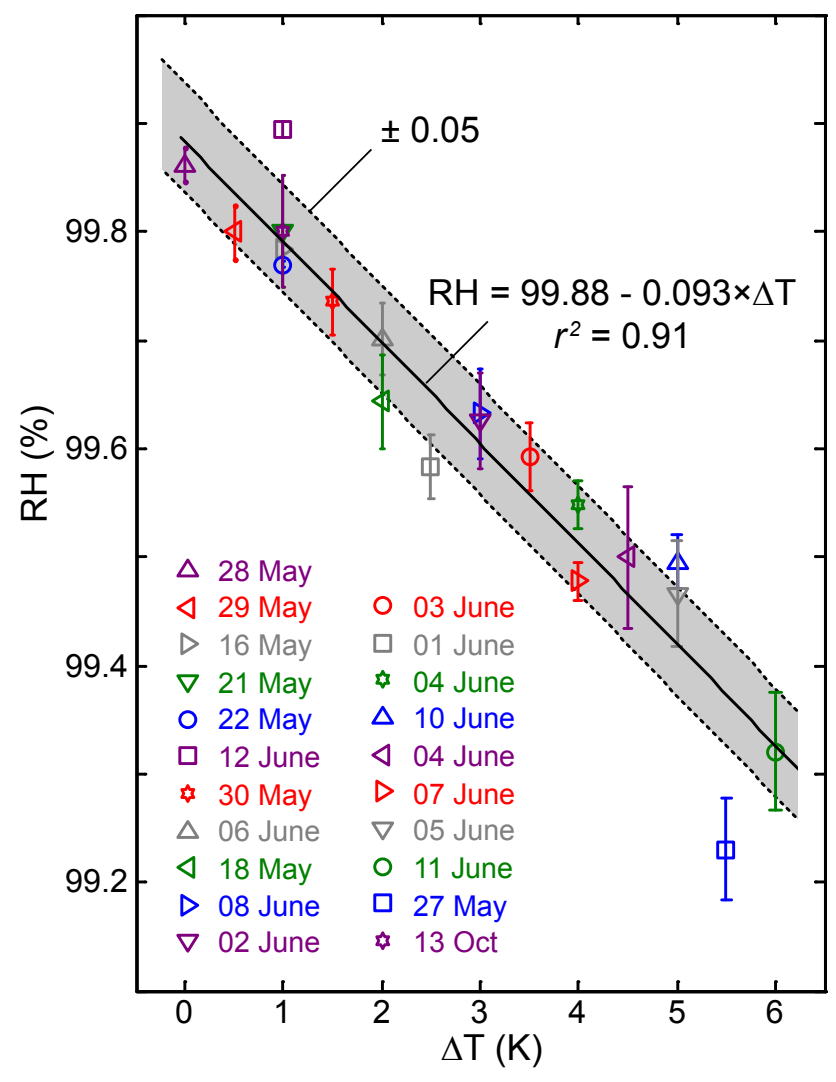

Fig. 4. RH vs. $\triangle T$, with $\mathrm{RH}$ derived from observed $D_{\text {wet }}$ of $\mathrm{NaCl}$ solution droplets, assuming $\kappa=1.24$ to 1.27 (based on the E-AIM model) and shape-corrected diameter $(\chi=1.08)$.

ammonium sulfate (AS $\kappa=0.572 \pm 0.074)$. Average AS $\kappa$ was $21 \%$ lower than the ideal value $(0.72)$ but in agreement with the value predicted from macroscopic observations (Timmermans, 1960). If the nonideality of AS is incorporated into the van't Hoff factor, this is equivalent to an average value of $\nu=2.4$, although as discussed below this value increases over the RH range studied here. Although not found in atmospheric particles (Facchini et al., 2001), sodium dodecyl sulfate (SDS) is a commonly studied surfactant, and as such it was used as a model surface-active compound. The average high-RH hygroscopicity of SDS $(\kappa=0.134 \pm 0.029)$ was only 9\% lower than that predicted for an ideal solution (0.147). In macroscopic solutions, however, SDS does not behave ideally: $\phi$ drops sharply to 0.12 (equivalent to $\kappa=0.02$ ) once the critical micelle concentration (CMC, $8.2 \mathrm{~mol} \mathrm{~m}^{-3}$ ) is exceeded, and remains at $\sim 0.12$ for all [SDS] observed in this study $\left(>110 \mathrm{~mol} \mathrm{~m}^{-3}\right.$ ) (Widera et al., 2003). The values of SDS $\kappa$ derived from $D_{\text {wet }}$ observations therefore suggest that a lack of micellization in micron-sized solution droplets enhances SDS aerosol hygroscopicity at high RH relative to that of a macroscopic solution. The relative hygroscopicity of the organic compounds was as predicted from their molar volumes and assuming an ideal solution (Table 1). Malonic 


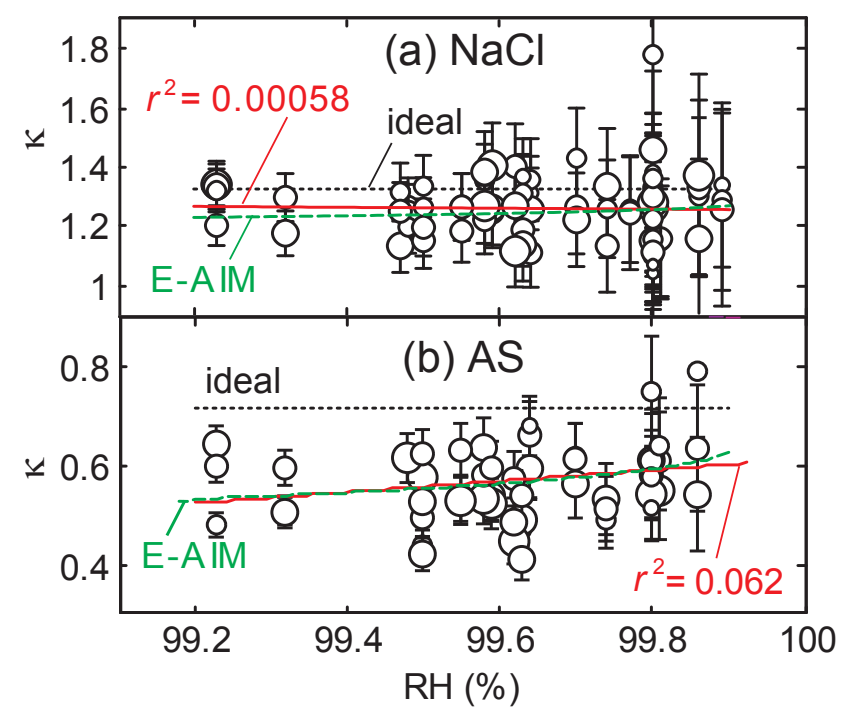

Fig. 5. Hygroscopicity ( $\kappa$ ) of (a) $\mathrm{NaCl}$ and (b) AS vs. RH. With linear regressions (red solid lines), data from macroscopic solutions as represented in the E-AIM model (green dashed lines), and values for ideal solutions with the surface tension of water (black dotted lines). Symbol size indicates $D_{\text {dry }}$. Error bars indicate the error in $\kappa$ associated with an error in RH of $\pm 0.5 \%$ (absolute).

acid was the most hygroscopic organic compound $(\kappa=0.29)$, followed by adipic acid (0.19), glucose (0.17), sodium dodecyl sulfate (0.13), and sucrose (0.11). Malonic acid $\kappa$ was only slightly above the theoretical value assuming ideality and no dissociation. Glucose hygroscopicity was also slightly greater than that predicted for an ideal solution. In contrast, sucrose hygroscopicity was 25 to $50 \%$ greater than that predicted assuming ideality. Adipic acid hygroscopicity was relatively high, especially in light of negligible adipic acid hygroscopicity at RH up to 95\% observed previously (Prenni et al., 2001; Sjogren et al., 2007). This could be due to the relatively large size $\left(D_{\text {dry }} \geqslant 250 \mathrm{~nm}\right)$ of adipic acid particles examined, which are not subject to the deliquescence barrier to hygroscopic growth affecting smaller $\left(D_{\text {dry }}<150 \mathrm{~nm}\right)$ particles (Hings et al., 2008).

\subsection{Hygroscopicity variation with $\mathrm{RH}$}

\subsubsection{Inorganic compounds}

Because $\mathrm{NaCl}$ was used as the reference substance (Fig. 4), variation of $\kappa$ with $\mathrm{RH}$ was determined by experimental $\mathrm{NaCl}$ water activity data, as incorporated into the E-AIM water activity model, and increased from 1.24 at $\mathrm{RH}=99.2 \%$ to 1.27 at $\mathrm{RH}=99.9 \%$, a small variation relative to that due to experimental uncertainty (Fig. 5a). $\kappa$ of ammonium sulfate (derived from observations of $D_{\text {wet }}$ ) increased slightly as RH increased from 99 to $100 \%$, as predicted using macroscopic water activity measurements (represented by E-AIM, see Fig. 5b). Although this trend had only mild statistical
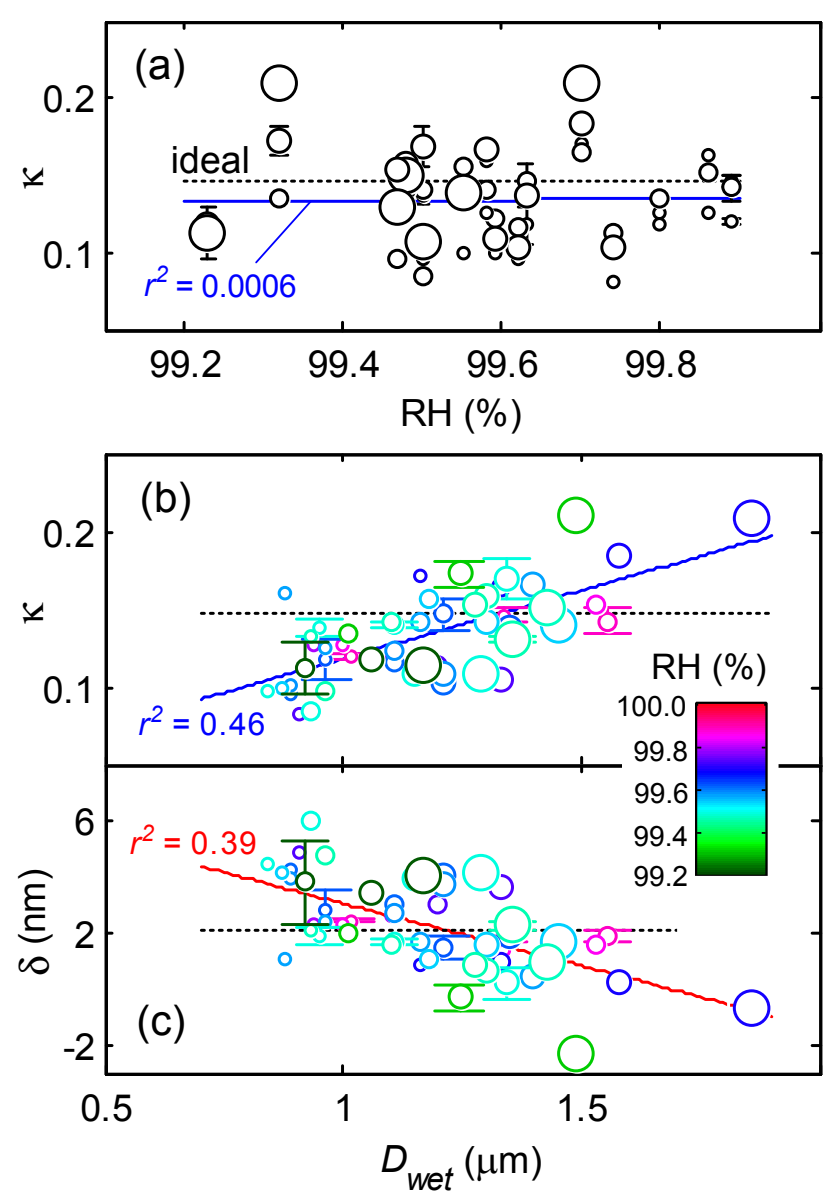

Fig. 6. SDS hygroscopicity, with linear regressions (red solid lines) and values for ideal solutions with the surface tension of water (black dotted lines). Symbol size indicates $D_{\text {dry }}$. Error bars indicate duplicate $D_{\text {wet }}$ standard deviations. (a) $\kappa$ vs. RH. (b) $\kappa$ vs. $D_{\text {wet }}$. (c) $\delta$ vs. $D_{\text {wet }}$.

significance ( $p=0.068$, see Table 1 ), the excellent match between the observations and the E-AIM predictions suggests that micron-sized AS solution droplets can be described by macroscopic data. If this nonideality were to be incorporated into the van't Hoff factor, it would increase from $v=2.2$ to 2.5 as RH increases from 99.2 to $99.9 \%$, suggesting that a value larger than 2.5 should be used in calculations involving activation of AS particles under supersaturated conditions.

\subsubsection{SDS}

In macroscopic aqueous solutions, the ability of SDS to lower water activity $\left(a_{\mathrm{w}}\right)$ is strongly limited by its tendency to form micelles, and therefore the hygroscopicity of an SDS particle might be expected to increase with increasing $\mathrm{RH}$, as greater dilution would reduce the proportion of SDS found in micelles. However, as with $\mathrm{NaCl}$, SDS $\kappa$ did not vary with RH (Fig. 6a). This indicates either that $\operatorname{SDS} \phi$ is relatively 


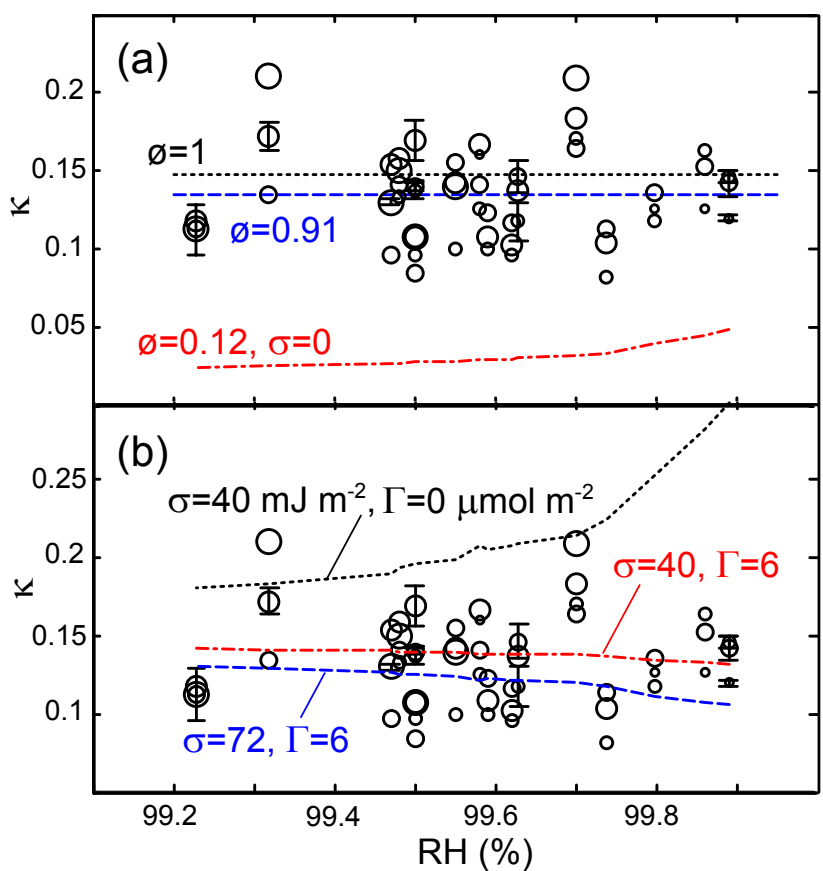

Fig. 7. Theoretical variation in SDS $\kappa$ with RH (lines) for several cases, with observations (black circles, size indicates $D_{\text {dry }}$ ). (a) Predicted $\kappa$ for three cases: an ideal solution droplet with the surface tension of pure water (black dotted line), a droplet with $\phi$ set to match average observed $\kappa$ and the surface tension of pure water (blue dashed line), and a droplet with $\phi$ limited by micellization and a surface tension of zero (red dash-dot line). Even when $\sigma=0$, micellization would result in droplets with $\kappa \sim \frac{1}{2}$ of the observed values. (b) Three cases related to surface activity: only surface tension reduction $\left(\sigma=40 \mathrm{~mJ} \mathrm{~m}^{-2}\right)$, only surface partitioning and $\Gamma=6 \mu \mathrm{mol} \mathrm{m}{ }^{-2}$ (dashed blue line), and both. When both surface effects are considered, they tend to cancel out in terms of their influence on $\kappa$ vs. RH.

constant at high $\mathrm{RH}$, or that variation in $\phi$ is roughly canceled out by SDS surface activity in terms of its influence on hygroscopicity. To further investigate this lack of variation, we make several assumptions regarding the water activity of SDS solution droplets, and compare the predicted variation in SDS $\kappa$ with RH to observations. Some of these predictions are based on the CMC of SDS $\left(8.2 \mathrm{~mol} \mathrm{~m}^{3}\right)$, and we note again that based on measured $D_{\text {dry }}$ and $D_{\text {wet }}$, the range of SDS concentrations observed in this study is 110 to $340 \mathrm{~mol} \mathrm{~m}^{-3}$.

Our first two cases assume that SDS either behaves ideally $(\phi=1)$ or $\phi=0.91$ (as required to match observed $\kappa$ ). In both cases, the surface tension of the droplet is assumed to be equal to that of pure water. The resulting values of SDS $\kappa$ are constant with RH (Fig. 7a) both because $\phi$ is constant and $\sigma=72.8 \mathrm{~mJ} \mathrm{~m}^{-2}$ (the assumed value in the $\kappa$ formulation, see Eq. 5). Additionally, the theoretical $\kappa$ values are roughly consistent with the observed values. However, if it is instead assumed that $\phi=0.12$, as derived from macroscopic

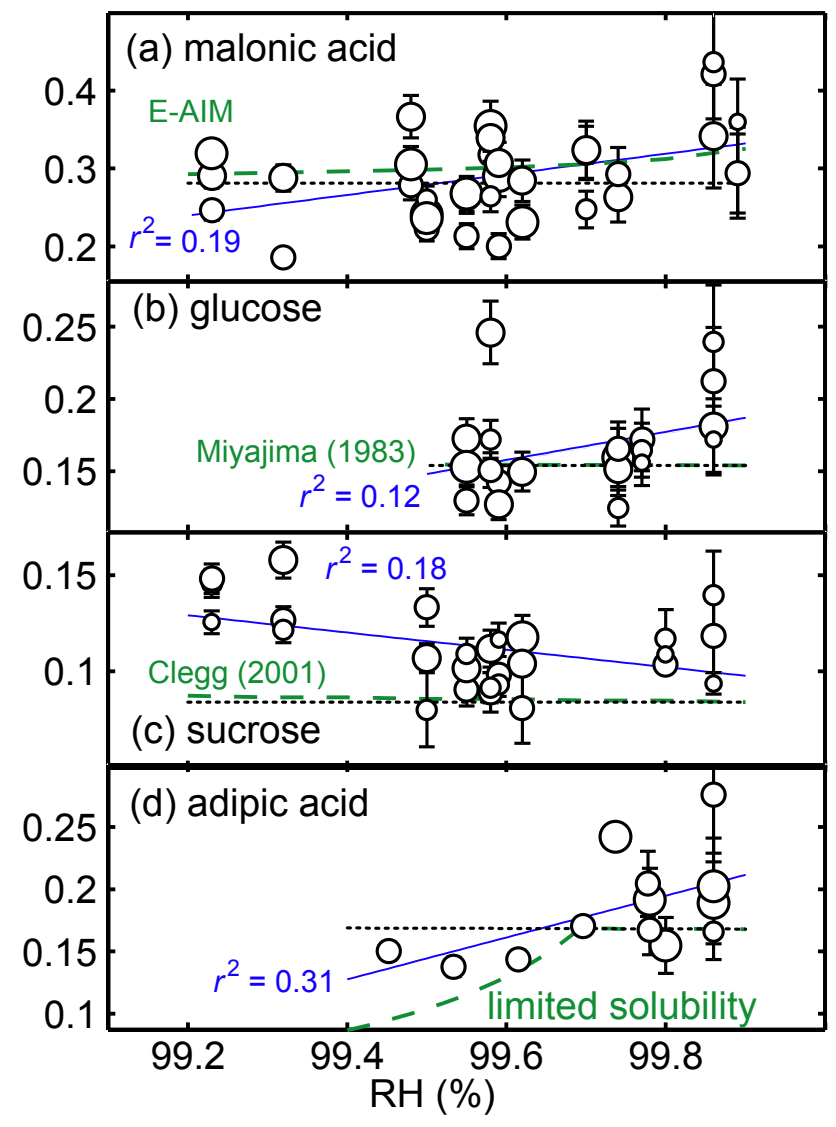

Fig. 8. Organic hygroscopicity $(\kappa)$ vs. RH. With linear regressions (red solid lines), values for ideal solutions with the surface tension of water (black dotted lines), and theoretical values (green dashed lines). Marker size indicates $D_{\mathrm{dry}}$. Error bars indicate the error in $\kappa$ associated with an error in RH of $\pm 0.05 \%$ (absolute). (a) malonic acid. (b) glucose. (c) sucrose. (d) adipic acid.

SDS solutions, $\kappa$ is much smaller than in our observations (Fig. 7a, red curve). Not even the assumption that $\sigma$ is reduced to zero can make the choice of $\phi=0.12$ consistent with the observations. We therefore conclude that micellization in micron-sized SDS solution droplets does not increase $a_{\mathrm{w}}$ at RH from 99 to $100 \%$ in a manner analogous to macroscopic solutions; and therefore, $\mathrm{CMC}$ values obtained from measurements of such solutions may not be appropriate for calculations involving aerosol particles of typical atmospheric sizes (e.g., Tabazadeh, 2005).

\subsubsection{Other organic compounds}

The hygroscopicity of the remaining compounds, expressed as $\kappa$, increased with RH, with the exception of sucrose. These trends were significant for malonic acid $(p<0.01)$ and sucrose $(p<0.03$, Table 1$)$. Like AS, the increase of malonic acid $\kappa$ with RH was consistent with the E-AIM activity coefficient model (Fig. 8a), and values of $\kappa>\kappa_{\text {ideal }}$ around 
Table 2. Slopes $(m)$ and significance ( $p$-value) of trends in both hygroscopicity parameters ( $\kappa$ and $\delta$ ) with $D_{\text {wet }} p$-values under $5 \%$ are in boldface.

\begin{tabular}{lrrll}
\hline & $\begin{array}{r}m_{\kappa} \\
{\left[\% \mathrm{~m} \mathrm{~m}^{-1}\right]}\end{array}$ & $\begin{array}{r}m_{\delta} \\
{\left[\% \mathrm{mum}^{-1}\right]}\end{array}$ & $p_{\kappa}$ & $p_{\delta}$ \\
\hline $\mathrm{NaCl}$ & 3.3 & -8.1 & 0.13 & 0.26 \\
$\mathrm{AS}$ & 4.5 & -0.5 & 0.42 & 0.98 \\
malonic acid & 41 & -120 & $\mathbf{0 . 0 0 1}$ & $\mathbf{0 . 0 1 4}$ \\
adipic acid & 47 & -27 & $\mathbf{0 . 0 1 5}$ & 0.52 \\
glucose & 42 & -76 & $\mathbf{0 . 0 3 3}$ & 0.085 \\
SDS & 65 & -210 & $\mathbf{1} \times \mathbf{1 0}^{-6}$ & $\mathbf{1} \times \mathbf{1 0}^{-6}$ \\
sucrose & 22 & -100 & 0.26 & 0.051 \\
\hline
\end{tabular}

$\mathrm{RH}=99.8 \%$ are likely due to dissociation ( $\kappa$ was calculated assuming no dissociation).

Glucose $\kappa$ increased slightly with RH (Fig. 8b). Unlike the inorganic compounds, for glucose $\phi>1$ in aqueous solutions (e.g., Matubayasi and Nishiyama, 2006), from which $\kappa>\kappa_{\text {ideal }}$ follows. At the high RH observed in this study, glucose concentration was between 0.11 to $0.45 \mathrm{~mol} \mathrm{~kg}^{-1}$, which in macroscopic solutions corresponds to an increase in $\phi$ of $<2 \%$ (Stokes and Robinson, 1966), and thus this effect would have to be enhanced in micron-sized droplets to account for the observations.

Sucrose was the only compound studied in which $\kappa$ decreased with RH (Fig. 8c), although for all RH, $\kappa>\kappa_{\text {ideal }}$. Like glucose, the osmotic coefficient of macroscopic sucrose solutions is greater than one, although sucrose deviates further from ideality (which is consistent with our observations). At the maximum sucrose concentration observed $\left(0.53 \mathrm{~mol} \mathrm{~kg}^{-1}\right), \phi=1.044$ in macroscopic solutions (Clegg et al., 2001), again suggesting that this effect is enhanced in micron-sized droplets relative to macroscopic solutions. The ratio of glucose $\kappa$ to sucrose $\kappa$ increases towards 1.8 (the ratio of their molar volumes, as assumed for ideal solutions) as $\mathrm{RH} \rightarrow 100 \%$. The greater non-ideality of sucrose relative to glucose is already apparent at $\mathrm{RH} \sim 99.5 \%$.

An increase in adipic acid $\kappa$ with RH (Fig. 8d) could also at least partly be caused by its low solubility of $25 \mathrm{~kg} \mathrm{~m}^{-3}$ (Saxena and Hildemann, 1996). Again assuming $\phi=1$, this solubility limit corresponds to an RH of $\sim 99.7 \%$. Adipic acid $\kappa$ does decrease below this limit, although it is consistently larger than predicted without accounting for dissociation (or Kelvin effects).

\subsection{Hygroscopicity variation with $D_{\text {wet }}$}

\subsubsection{Comparison of $\kappa$ and $\delta$ as a hygroscopicity parameter vs. $D_{\text {wet }}$}

We first compared $\kappa$ and $\delta$ as a parameter for trends in hygroscopicity with $D_{\text {wet }}$ to see if there was any justification

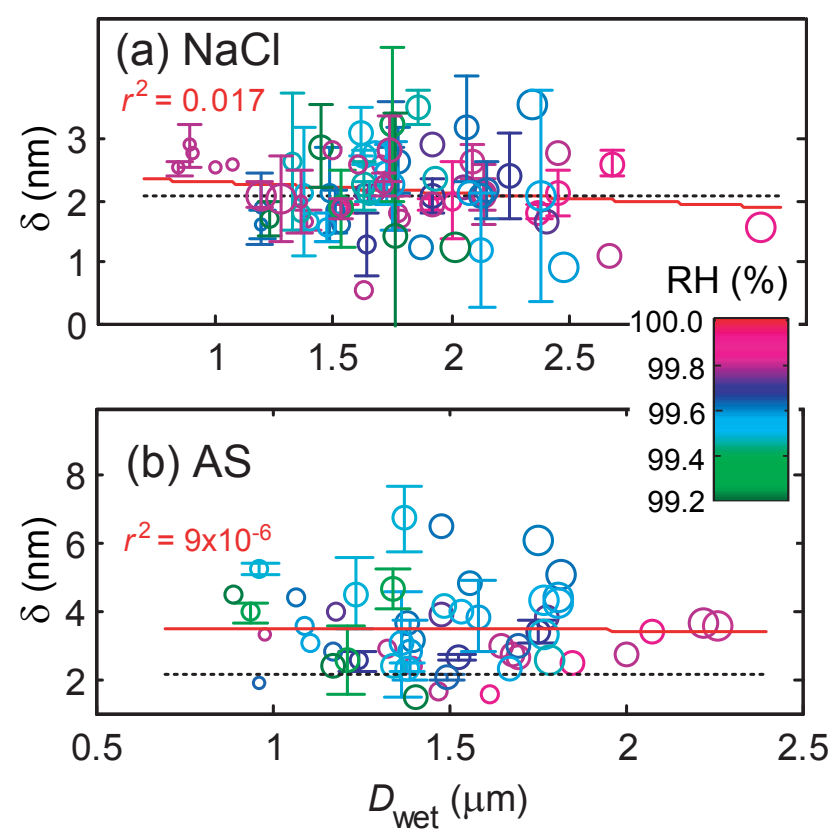

Fig. 9. Hygroscopicity $(\delta)$ of (a) $\mathrm{NaCl}$ and (b) AS vs. $D_{\text {wet }}$. With linear regressions (red solid lines) and values for ideal solutions with the surface tension of water (black dotted lines). Marker size indicates $D_{\text {dry }}$. Error bars indicate duplicate $D_{\text {wet }}$ standard deviations.

for a second parameter. Calculation of $\delta$ requires assumption of $\phi$ (i.e., the Raoult effect), and we allow $\phi$ to vary with RH according to the linear regression of $\kappa$ onto RH (red lines in Figs. 5, 6a, and 8). Because $\delta$ accounts for variation of osmolarity with $\mathrm{RH}$, it is less likely that any trend in $\delta$ with $D_{\text {wet }}$ is due to solution non-ideality than if $\phi$ were held constant. We therefore expect $\delta$ to be a more appropriate metric of Kelvin effects. This can be seen by comparing the $p$ values for these parameters (Table 2), which are generally higher (less significant) for $\delta . \delta$ for only two compounds (SDS and malonic acid) varied significantly $(p<0.05)$ with $D_{\text {wet }}$, while variation of $\kappa$ with $D_{\text {wet }}$ was significant for two additional compounds (glucose and adipic acid). Figure $6 \mathrm{~b}$ and c show the trend in SDS hygroscopicity with $D_{\text {wet }}$ using $\kappa$ and $\delta$, respectively. The trends are in opposite direction because hygroscopicity decreases with $\delta$, but the significance (Table 2) and the correlation are similar. Based on the results from all compounds, we conclude that a parameterization of the Kelvin term such as $\delta$, that is derived accounting for nonideality in the Raoult term, is a more conservative and useful metric of Kelvin effects in micron-sized droplets.

\subsubsection{Inorganic compounds}

Neither $\mathrm{NaCl}$ nor AS $\delta$ varied with $D_{\text {wet }}$ (Fig. 9), as expected because these salts are not known to be surface-active. The finding that non-ideal behavior of AS, as opposed to surface 

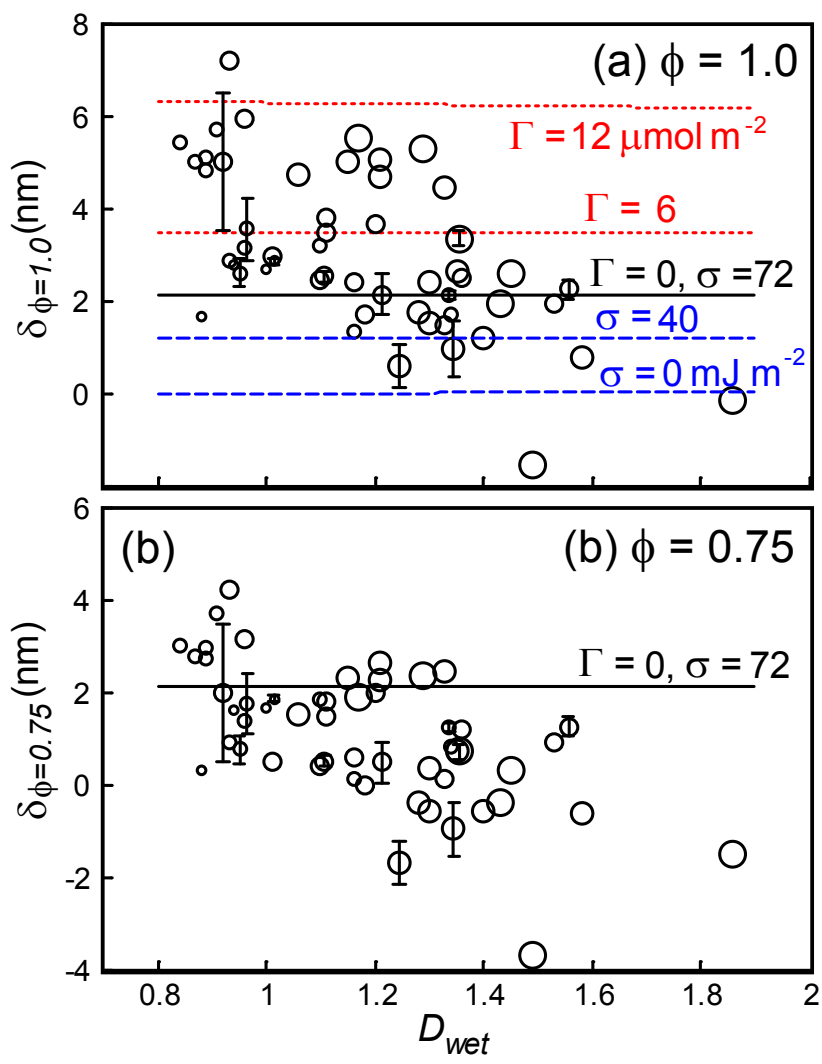

Fig. 10. (a) SDS $\delta$ both observed (black circles, size indicates $D_{\text {dry }}$ ) and predicted (lines) under several assumptions regarding surface activity, versus $D_{\text {wet }}$. Surface partitioning (i.e., $\Gamma>0$ ) tends to decrease hygroscopicity, or increase $\delta$, while surface tension reduction $\left(\sigma_{i} 72 \mathrm{~mJ} \mathrm{~m}^{-2}\right)$ has the opposite effect. (b) Observed $\delta$ with all calculations of $\delta$ made assuming $\phi=0.75$. This results in a downward shift in all $\delta$, but has only a minor effect on the trend in $\delta$ with $D_{\text {wet }}$.

activity, causes variation in high-RH hygroscopicity is consistent with LACIS measurements (Wex et al., 2005).

\subsubsection{Sodium Dodecyl Sulfate (SDS)}

It is well-known that SDS reduces the surface tension $(\sigma)$ of macroscopic aqueous solutions, and consequently one might expect SDS $\delta$ to be lower than that of $\mathrm{NaCl}$ and AS. SDS hygroscopicity did vary strongly with $D_{\text {wet }}$ (Fig. 6b and c), although it is not immediately clear why its surface activity causes its hygroscopicity to increase with increasing $D_{\text {wet }}$, as a given reduction in surface tension would be expected to cause a decrease in $\delta_{\text {SDS }}$ which does not vary with $D_{\text {wet }}$ (Fig. 2c). We next seek to explain the trend in $\delta$ with respect to $D_{\text {wet }}$ as shown in Fig. 6c (and reproduced in Fig. 10). To do so, we make a series of assumptions regarding SDS surface activity, and discuss the theoretical variation in $\kappa$ with $\mathrm{RH}$ and $\delta$ with $D_{\text {wet }}$ resulting from these assumptions.
As can be seen in Eq. (6), $\delta$ is proportional to surface tension $(\sigma)$. If SDS solution droplets behave ideally, with a surface tension of pure water, $\delta$ is equal to $2.1 \mathrm{~nm}$, and $\delta=0$ if the Kelvin effect is completely neglected (Fig. 10a). Taking the partitioning effect into account has the opposite effect: formation of a monolayer (surface excess concentration, $\Gamma$, of $6 \mu \mathrm{mol} \mathrm{m}{ }^{-2}$ ) causes $\delta$ to increase to $3.6 \mathrm{~nm}$ (Fig. 10a). With a soluble surfactant such as SDS, the solute excess may exist for some distance below the solution-air interface, and thus concentrations greater than one monolayer equivalent are physically reasonable. Note that like $\sigma$, the influence of $\Gamma$ on hygroscopicity goes as $D_{\text {wet }}^{-1}$, and therefore $\delta$ is constant with $D_{\text {wet }}$.

Transformation of observed $D_{\text {wet }}$ into $\delta$ requires an assumption of $\phi$ for the solution droplets. As with all other compounds, for SDS we assumed that $\phi$ varies with RH according to the linear regression of $\kappa$ onto RH (for SDS, $\phi$ was relatively constant, roughly 0.9 ). To test the sensitivity of the trend in $\delta$ with $D_{\text {wet }}$ to this assumption, we repeat the calculations assuming $\phi=0.75$ (Fig. 10b). This causes a slight downward shift in all $\delta$, but the trend in $\delta$ with $D_{\text {wet }}$ is not fundamentally altered.

It can be seen in Fig. 10a that lowering $\sigma$ (blue curves) and accounting for the partitioning effect (red curves) have opposite effects on SDS hygroscopicity (parametrized as $\delta$ ). When both are taken into account, they tend to cancel each other out, and if they are roughly in balance, no trend in hygroscopicity with RH would be predicted (Fig. 7b). The lack of a trend in SDS $\kappa$ with RH therefore suggests the presumed lowering of $\sigma$ is roughly canceled out by the partitioning effect.

As indicated above, we have not been able to model the observed increase in SDS hygroscopicity (decrease in $\delta_{\text {SDS }}$ ) with $D_{\text {wet }}$ assuming constant values of $\phi, \sigma$, and $\Gamma$. This suggests that at least one of these parameters varies with $D_{\text {wet }}$. Because $\kappa$ is roughly proportional to $\phi$, and the highest observed values of $\kappa_{\mathrm{SDS}}$ are roughly 2 times greater than the lowest, the range of observed SDS hygroscopicity could correspond to an increase in $\phi$ from 0.5 to 1 . This could result from micellization in smaller droplets, although not to the extent seen in macroscopic solutions. However, $\phi$ is typically thought to vary with concentration, and thus a trend in $\kappa$ SDS with RH would be expected if $\phi$ is not constant. It is therefore unlikely that the trend in $\delta$ is the result of micellization.

Figure $7 \mathrm{~b}$ demonstrates that if both $\sigma$ and $\Gamma$ are allowed to vary with $D_{\text {wet }}$, they can do so in a way that their influences on the $\kappa$ vs. RH trend cancel out. We found that the following assumptions fit the observations: At the low end of our measured $D_{\text {wet }}(0.8 \mu \mathrm{m})$, we set $\Gamma$ to $18 \mu \mathrm{mol} \mathrm{m}^{-2}$, and decreased $\Gamma$ linearly with $D_{\text {wet }}$ until $\Gamma=0$ when $D_{\text {wet }}=1.8 \mu \mathrm{m}$. We held $\sigma$ constant at $30 \mathrm{~mJ} \mathrm{~m}^{-2}$. Under these assumptions, $\kappa$ does not vary with RH (Fig. 11a), but $\delta$ would decrease with $D_{\text {wet }}$ at roughly the observed rate (Fig. 11b). We emphasize that because two effects are opposing each other (surface tension reduction and partitioning), we cannot isolate either effect 

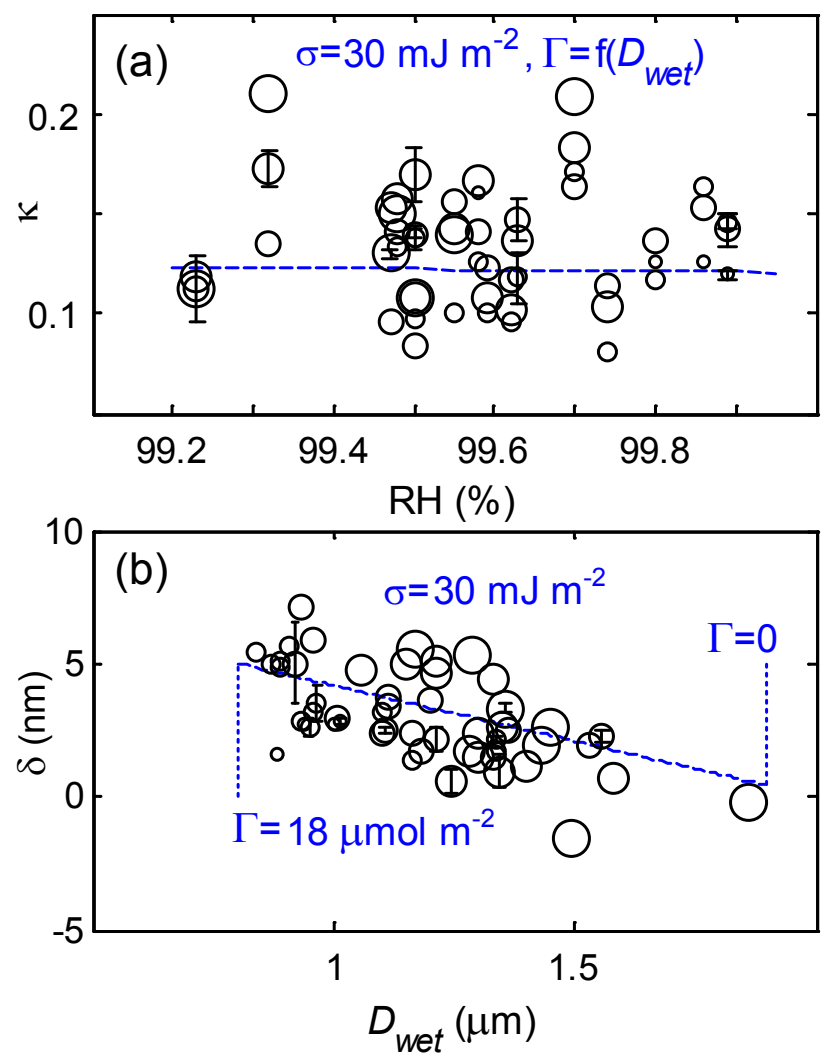

Fig. 11. Observed trends in SDS hygroscopicity with RH and $D_{\text {wet }}$ (black circles, size indicates $D_{\text {dry }}$ ), and predictions (blue dashed lines) assuming $\phi=1$, and that as $D_{\text {wet }}$ increases from 0.8 to $1.8 \mu \mathrm{m}, \Gamma$ decreases linearly from 18 to $0 \mu \mathrm{mol} \mathrm{m}^{-2} . \sigma$ is held constant at $30 \mathrm{~mJ} \mathrm{~m}^{-2}$.

and thus these values can not be considered independent estimates. In other words, this model is an ad hoc fit to the data, and while we can conclude that SDS hygroscopicity increases with increasing $D_{\text {wet }}$, the mechanism responsible for this trend remains unclear.

As discussed previously, a value of $\Gamma$ corresponding to the actual size of the SDS molecule is $6 \mu \mathrm{mol} \mathrm{m}{ }^{-2}$ if a monolayer is present. Previous investigations have characterized two types of organic films at aqueous interfaces: "condensed" films formed by insoluble organic matter, which resides only at the aqueous-air interface, and "adsorbed" films formed by soluble organic matter. Because SDS is a soluble surfactant, its surface excess might occur both at the interface, but also as an increased dissolved concentration near the interface (i.e., a gradient from the interface to the bulk). In other words, if the surface excess concentration is $18 \mu \mathrm{mol} \mathrm{m}{ }^{-2}$ but only $6 \mu \mathrm{mol} \mathrm{m}{ }^{-2}$ can reside in a monolayer at the interface, then for every SDS molecule in the monolayer, there are two in solution near the interface in excess of the bulk solution concentration. This interpretation of the surface excess concentration is supported by measurements of evaporation rates from SDS solutions, which are similar to those of

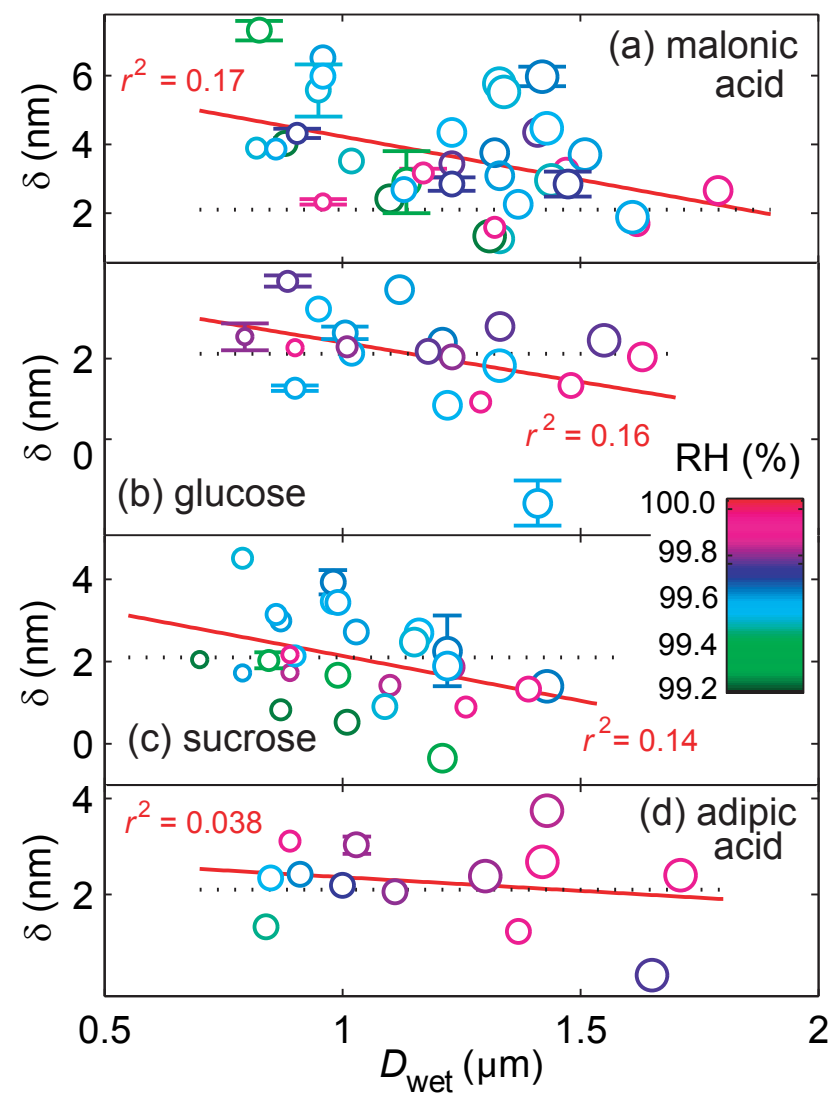

Fig. 12. Organic hygroscopicity $(\delta)$ vs. $D_{\text {wet }}$. With linear regressions (red solid lines), and values for ideal solutions with the surface tension of water (black dotted lines). Error bars, symbol size, and color indicate duplicate $D_{\text {wet }}$ standard deviations, dry diameter, and $\mathrm{RH}$, respectively. (a) malonic acid. (b) glucose. (c) sucrose. (d) adipic acid.

pure water. In contrast, a compressed film of insoluble surfactant can substantially reduce evaporation rates from aqueous solutions (Moroi et al., 2004). However the same effect could result from any mechanism causing a decrease in SDS solution activity that goes as $D_{\text {wet }}^{-1}$. However, if $\sigma$ of these droplets is somewhere between the value for pure water and zero, and micellization is not occurring, then the most likely explanation for the observed trend is an increase in $\Gamma$ with decreasing $D_{\text {wet }}$, eventually reaching a value equivalent to approximately three monolayers.

\subsubsection{Other organic compounds}

The hygroscopicity of all other organic compounds increased with size (i.e., $\delta$ decreased with $D_{\text {wet }}$, although none as strongly as SDS (Fig. 12). As with the variation of hygroscopicity with RH, this trend was strongest (Fig. 12a) and most significant ( $p=0.014$, Table 2 ) for malonic acid, followed by sucrose. These results therefore provide evidence that both the Raoult and Kelvin effects influence the high-RH 
hygroscopicity of malonic acid and, to a lesser extent, sucrose. It is also possible that the Kelvin effect contributes to the hygroscopicity of both sugars. While glucose is known to slightly raise the surface tension of aqueous solutions, sucrose has the opposite effect (Matubayasi and Nishiyama, 2006), and this is consistent with sucrose $\delta$ being lower on average than glucose $\delta$. The change in $\sigma$ of macroscopic solutions caused by these sugars is slight relative to SDS, however, particularly at low concentrations. Furthermore, without independent knowledge of the osmolarity of these droplets, the importance of the Kelvin effect on sugar hygroscopicity cannot be quantified. No impact of the Kelvin effect on adipic acid hygroscopicity was seen once observed variations in $\phi$ with RH were accounted for (Fig. 12d, Table 2).

\section{Conclusions}

The hygroscopicity of particles of seven pure compounds was measured at RH ranging from 99.2 to $99.9 \%$, and expressed as $\kappa$ to examine the Raoult effect and as $\delta$ to examine the Kelvin effect. The results were broadly consistent with those predicted based on literature values for molar volume and water activity. Specifically, we draw the following conclusions:

1. Small variations in inorganic hygroscopicity are best explained by non-ideal solution effects. No trends with $D_{\text {wet }}$ were observed, and minor variation in hygroscopicity with RH was consistent with water activity data from macroscopic solutions.

2. Both Kelvin (curvature) and Raoult (solute) effects are important for the hygroscopicity of the tested organic aerosol. Trends with RH, when present, were consistent with water activity data. However, even when this variability was accounted for, organic hygroscopicity generally increased with increasing $D_{\text {wet }}$, particularly for the most surface active compound, sodium dodecyl sulfate (SDS).

3. Surface activity reduces the hygroscopicity of SDS at high $R H$. This occurs because in this RH range (99 to $100 \%$ ), the partitioning effect overwhelms the reduction in $\sigma$. The concentrations observed in this study are greater than would be found at the point of activation, however, and so it is likely that the surface excess concentration is greater in these droplets than in newlyformed cloud droplets. It is therefore possible that slightly reduced surface tension $(\sim 10 \%)$ inferred from recent $\mathrm{CCN}$ activity experiments of complex organic solutions (e.g., Engelhart et al., 2008; Abbatt et al., 2005; Ziese et al., 2008; Wex et al., 2009; Moore et al., 2008) could be a result of less partitioning relative to surface tension reduction under supersaturated conditions.
4. No evidence for micellization of SDS is found in these drops, at least to the extent seen in macroscopic solutions. SDS hygroscopicity was several times greater (in terms of water volume absorbed) than predicted based on macroscopic data.

5. Overall, these results suggest that extending the properties of macroscopic solutions to calculations of the hygroscopicity of micron-sized drops can be very misleading.

Acknowledgements. The authors would like to acknowledge funding from the NASA Radiation Sciences Program and the NSF Graduate Research Fellowship program.

Edited by: A. Laaksonen

\section{References}

Abbatt, J. P. D., Broekhuizen, K., and Kumal, P. P.: Cloud condensation nucleus activity of internally mixed ammonium sulfate/organic acid aerosol particles, Atmos. Environ., 39, 4767 4778, doi:10.1016/j.atmosenv.2005.04.029, 2005.

Abdul-Razzak, H. and Ghan, S. J.: Parameterization of the influence of organic surfactants on aerosol activation, J. Geophys. Res.-Atmos., 109, 1-11, doi:10.1029/2003JD004043, 2004.

Asa-Awuku, A., Sullivan, A. P., Hennigan, C. J., Weber, R. J., and Nenes, A.: Investigation of molar volume and surfactant characteristics of water-soluble organic compounds in biomass burning aerosol, Atmos. Chem. Phys., 8, 799-812, 2008,

http://www.atmos-chem-phys.net/8/799/2008/.

Bachalo, W.: Method for measuring the size and velocity of spheres by dual-beam light-scatter interferometry, Appl. Optics, 19, 363370, 1980.

Bachalo, W. and Houser, M.: Phase Doppler spray analyzer for simultaneous measurements of drop size and velocity distributions, Opt. Eng., 23, 583-590, 1984.

Broekhuizen, K., Kumar, P., and Abbatt, J.: Partially soluble organics as cloud condensation nuclei: Role of trace soluble and surface active species, Geophys. Res. Lett., 31, 1-5, doi: 10.1029/2003GL018203, 2004.

Chan, M. N., Kreidenweis, S. M., and Chan, C. K.: Measurements of the hygroscopic and deliquescence properties of organic compounds of different solubilities in water and their relationship with cloud condensation nuclei activities, Environ. Sci. Technol., 42, 3602-3608, doi:10.1021/es7023252, 2008.

Chang, C. and Franses, E.: Adsorption dynamics of surfactants at the air-water interface - a critical review of mathematicalmodels, data, and mechanisms, Colloid. Surface. A, 100, 1-45, 1995.

Chang, C., Wang, N., and Franses, E.: Adsorption dynamics of single and binary surfactants at the air-water interface, Colloid. Surface., 62, 321-332, 1992.

Clegg, S., Seinfeld, J., and Brimblecombe, P.: Thermodynamic modelling of aqueous aerosols containing electrolytes and dissolved organic compounds, J. Aerosol Sci., 32, 713-738, 2001.

Clegg, S. L., Seinfeld, J. H., and Brimblecombe, P.: A thermodynamic model of the system $\mathrm{H}^{+}-\mathrm{NH}_{4}^{+}-\mathrm{Na}^{+}-\mathrm{SO}_{4}^{2-}-\mathrm{NO}_{3}^{-}-\mathrm{Cl}^{-}$. $\mathrm{H}_{2} \mathrm{O}$ at 298.15 K, J. Phys. Chem. A, 102, 2155-2171, 1998. 
Clegg, S. L., Seinfeld, J. H., and Brimblecombe, P.: Thermodynamic modelling of aqueous aerosols containing electrolytes and dissolved organic compounds, J. Aerosol Sci., 32, 713-738, 2001.

Dinar, E., Taraniuk, I., Graber, E. R., Katsman, S., Moise, T., Anttila, T., Mentel, T. F., and Rudich, Y.: Cloud Condensation Nuclei properties of model and atmospheric HULIS, Atmos. Chem. Phys., 6, 2465-2482, 2006, http://www.atmos-chem-phys.net/6/2465/2006/.

Dinar, E., Taraniuk, I., Graber, E. R., Anttila, T., Mentel, T. F., and Rudich, Y.: Hygroscopic growth of atmospheric and model humic-like substances, J. Geophys. Res.-Atmos., 112, 1-13, doi: 10.1029/2006JD007442, 2007.

Duplissy, J., Gysel, M., Alfarra, M. R., Dommen, J., Metzger, A., Prevot, A. S. H., Weingartner, E., Laaksonen, A., Raatikainen, T., Good, N., Turner, S. F., McFiggans, G., and Baltensperger, U.: Cloud forming potential of secondary organic aerosol under near atmospheric conditions, Geophys. Res. Lett., 35, 1-5, doi: 10.1029/2007GL031075, 2008.

Ellison, G., Tuck, A., and Vaida, V.: Atmospheric processing of organic aerosols, J. Geophys. Res.-Atmos., 104, 11633-11641, 1999.

Engelhart, G. J., Asa-Awuku, A., Nenes, A., and Pandis, S. N.: $\mathrm{CCN}$ activity and droplet growth kinetics of fresh and aged monoterpene secondary organic aerosol, Atmos. Chem. Phys., 8, 3937-3949, 2008, http://www.atmos-chem-phys.net/8/3937/2008/.

Ervens, B., Feingold, G., and Kreidenweis, S.: Influence of watersoluble organic carbon on cloud drop number concentration, J. Geophys. Res.-Atmos., 110, 1-14, doi:10.1029/2004JD005634, 2005.

Facchini, M., Mircea, M., Fuzzi, S., and Charlson, R.: Cloud albedo enhancement by surface-active organic solutes in growing droplets, Nature, 401, 257-259, 1999.

Facchini, M., Mircea, M., Fuzzi, S., and Charlson, R.: Comments on "Influence of soluble surfactant properties on the activation of aerosol particles containing inorganic solute", J. Atmos. Sci., 58, 1465-1467, 2001.

Fitzgerald, J., Hoppel, W., and Vietti, M.: The size and scattering coefficient of urban aerosol-particles at Washington, DC as a function of relative-humidity, J. Atmos. Sci., 39, 1838-1852, 1982.

Gill, P., Graedel, T., and Weschler, C.: Organic films on atmospheric aerosol-particles, fog droplets, cloud droplets, raindrops, and snowflakes, Rev. Geophys., 21, 903-920, 1983.

Hanford, K. L., Mitchem, L., Reid, J. P., Clegg, S. L., Topping, D. O., and McFiggans, G. B.: Comparative thermodynamic studies of aqueous glutaric acid, ammonium sulfate and sodium chloride aerosol at high humidity, J. Phys. Chem. A, 112, 9413-9422, doi:10.1021/jp802520d, 2008.

Henning, S., Rosenørn, T., D’Anna, B., Gola, A. A., Svenningsson, B., and Bilde, M.: Cloud droplet activation and surface tension of mixtures of slightly soluble organics and inorganic salt, Atmos. Chem. Phys., 5, 575-582, 2005,

http://www.atmos-chem-phys.net/5/575/2005/.

Hings, S. S., Wrobel, W. C., Cross, E. S., Worsnop, D. R., Davidovits, P., and Onasch, T. B.: CCN activation experiments with adipic acid: effect of particle phase and adipic acid coatings on soluble and insoluble particles, Atmos. Chem. Phys., 8, 3735-
3748, 2008,

http://www.atmos-chem-phys.net/8/3735/2008/.

Hitzenberger, R., Berner, A., Kasper-Giebl, A., Loflund, M., and Puxbaum, H.: Surface tension of Rax cloud water and its relation to the concentration of organic material, J. Geophys. Res.Atmos., 107, 1-6, doi:10.1029/2002JD002506, 2002.

Hudson, J. and Da, X.: Volatility and size of cloud condensation nuclei, J. Geophys. Res.-Atmos., 101, 4435-4442, 1996.

Husar, R. and Shu, W.: Thermal analysis of Los Angeles smog aerosol, J. Appl. Meteorol., 14, 1558-1565, 1975.

Kiss, G., Tombacz, E., and Hansson, H.: Surface tension effects of humic-like substances in the aqueous extract of tropospheric fine aerosol, J. Atmos. Chem., 50, 279-294, doi: 10.1007/s10874-005-5079-5, 2005.

Kokkola, H., Sorjamaa, R., Peraniemi, A., Raatikainen, T., and Laaksonen, A.: Cloud formation of particles containing humiclike substances, Geophys. Res. Lett., 33, 1-5, doi:10.1029/ 2006GL026107, 2006.

Krämer, L., Pöschl, U., and Niessner, R.: Microstructural rearrangement of sodium chloride condensation aerosol particles on interaction with water vapor, J. Aerosol Sci., 31, 673-685, 2000.

Lewis, E. R.: An examination of Köhler theory resulting in an accurate expression for the equilibrium radius ratio of a hygroscopic aerosol particle valid up to and including relative humidity 100\%, J. Geophys. Res.-Atmos., 113, 1-17, doi:10.1029/ 2007JD008590, 2008.

Li, Z., Williams, A., and Rood, M.: Influence of soluble surfactant properties on the activation of aerosol particles containing inorganic solute, J. Atmos. Sci., 55, 1859-1866, 1998.

Lima, L. and Synovec, R.: Laser-based dynamic surface-tension detection for liquid-chromatography by probing a repeating drop radius, J. Chromatogr. A, 691, 195-204, 1995.

Loglio, G., Pandolfini, P., Tesei, U., and Noskov, B.: Measurements of interfacial properties with the axisymmetric bubbleshape analysis technique: effects of vibrations, Colloid. Surface. A, 143, 301-310, 1998.

Lohmann, U. and Leck, C.: Importance of submicron surface-active organic aerosols for pristine Arctic clouds, Tellus B, 57, 261268, 2005.

Matubayasi, N. and Nishiyama, A.: Thermodynamic quantities of surface formation of aqueous electrolyte solutions, VI. Comparison with typical nonelectrolytes, sucrose and glucose, J. Colloid Interf. Sci., 298, 910-913, doi:10.1016/j.jcis.2006.01.008, 2006.

Mircea, M., Facchini, M. C., Decesari, S., Cavalli, F., Emblico, L., Fuzzi, S., Vestin, A., Rissler, J., Swietlicki, E., Frank, G., Andreae, M. O., Maenhaut, W., Rudich, Y., and Artaxo, P.: Importance of the organic aerosol fraction for modeling aerosol hygroscopic growth and activation: a case study in the Amazon Basin, Atmos. Chem. Phys., 5, 3111-3126, 2005, http://www.atmos-chem-phys.net/5/3111/2005/.

Moroi, Y., Rusdi, M., and Kubo, I.: Difference in surface properties between insoluble monolayer and adsorbed film from kineic of water evaporation and BAM image, J. Phys. Chem. B, 108, 6351-6358, doi:10.1021/jp0306287, 2004.

Moore, R. H., Ingall, E. D., Sorooshian, A., and Nenes, A.: Molar mass, surface tension, and droplet growth kinetics of marine organics from measurements of CCN activity, Geophys. Res. Lett., 35, L07801, doi:10.1029/2008GL033350, 2008. 
Niedermeier, D., Wex, H., Voigtländer, J., Stratmann, F., Brüggemann, E., Kiselev, A., Henk, H., and Heintzenberg, J.: LACIS-measurements and parameterization of sea-salt particle hygroscopic growth and activation, Atmos. Chem. Phys., 8, 579590, 2008, http://www.atmos-chem-phys.net/8/579/2008/.

Petters, M. D. and Kreidenweis, S. M.: A single parameter representation of hygroscopic growth and cloud condensation nucleus activity, Atmos. Chem. Phys., 7, 1961-1971, 2007, http://www.atmos-chem-phys.net/7/1961/2007/.

Prenni, A. J., DeMott, P. J., Kreidenweis, S. M., Sherman, D. E., Russell, L. M., and Ming, Y.: The effects of low molecular weight dicarboxylic acids on cloud formation, J. Phys. Chem. A, 105, 11240-11248, 2001.

Prosser, A. and Franses, E.: Adsorption and surface tension of ionic surfactants at the air-water interface: review and evaluation of equilibrium models, Colloid. Surface. A, 178, 1-40, 2001.

Rissman, T., Nenes, A., and Seinfeld, J.: Chemical amplification (or dampening) of the Twomey effect: Conditions derived from droplet activation theory, J. Atmos. Sci., 61, 919-930, 2004.

Roberts, G. and Nenes, A.: A continuous-flow streamwise thermalgradient CCN chamber for atmospheric measurements, Aerosol Sci. Tech., 39, 206-221, 2005.

Ruehl, C. R., Chuang, P. Y., and Nenes, A.: How quickly do cloud droplets form on atmospheric particles?, Atmos. Chem. Phys., 8, 1043-1055, 2008, http://www.atmos-chem-phys.net/8/1043/2008/.

Ruehl, C. R., Chuang, P. Y., and Nenes, A.: Distinct CCN activation kinetics above the marine boundary layers along the California coast, Geophys. Res. Lett., 36, L15814, doi:10.1029/ 2009GL038839, 2009.

Russell, L., Maria, S., and Myneni, S.: Mapping organic coatings on atmospheric particles, Geophys. Res. Lett., 29, 1-4, doi:10. 1029/2002GL014874, 2002.

Saxena, P. and Hildemann, L.: Water-soluble organics in atmospheric particles: A critical review of the literature and application of thermodynamics to identify candidate compounds, J. Atmos. Chem., 24, 57-109, 1996.

Seidl, W. and Hanel, G.: Surface-active substances on rainwater and atmospheric particles, Pure Appl. Geophys., 121, 1077-1093, 1983.

Shulman, M., Jacobson, M., Carlson, R., Synovec, R., and Young, T.: Dissolution behavior and surface tension effects of organic compounds in nucleating cloud droplets, Geophys. Res. Lett., 23, 277-280, 1996.

Sjogren, S., Gysel, M., Weingartner, E., Baltensperger, U., Cubison, M. J., Coe, H., Zardini, A. A., Marcolli, C., Krieger, U. K., and Peter, T.: Hygroscopic growth and water uptake kinetics of twophase aerosol particles consisting of ammonium sulfate, adipic and humic acid mixtures, J. Aerosol Sci., 38, 157-171, 2007.

Sorjamaa, R. and Laaksonen, A.: The influence of surfactant properties on critical supersaturations of cloud condensation nuclei, J. Aerosol Sci., 37, 1730-1736, doi:10.1016/j.jaerosci.2006.07. 004, 2006.

Sorjamaa, R., Svenningsson, B., Raatikainen, T., Henning, S., Bilde, M., and Laaksonen, A.: The role of surfactants in Köhler theory reconsidered, Atmos. Chem. Phys., 4, 2107-2117, 2004, http://www.atmos-chem-phys.net/4/2107/2004/.
Stokes, R. H. and Robinson, R. A.: Interactions in aqueous nonelectrolyte solutions, I. Solute-solvent equilibria, J. Phys. Chem., 70, 2126-2131, doi:10.1021/j100879a010, 1966.

Szyszkowski, B.: Experimentelle studien über kapillare eigenschaften der wässerigen lösungen von fettsauren, Z. Phys. Chem., 64, 385-414, 1908.

Tabazadeh, A.: Organic aggregate formation in aerosols and its impact on the physicochemical properties of atmospheric particles, Atmos. Environ., 39, 5472-5480, doi:10.1016/j.atmosenv.2005. 05.045, 2005.

Taraniuk, I., Kostinski, A. B., and Rudich, Y.: Enrichment of surface-active compounds in coalescing cloud drops, Geophys. Res. Lett., 35, 1-5, doi:10.1029/2008GL034973, 2008.

Tervahattu, H., Hartonen, K., Kerminen, V., Kupiainen, K., Aarnio, P., Koskentalo, T., Tuck, A., and Vaida, V.: New evidence of an organic layer on marine aerosols, J. Geophys. Res.-Atmos., 107, 1-8, doi:10.1029/2000JD000282, 2002.

Textor, C., Schulz, M., Guibert, S., Kinne, S., Balkanski, Y., Bauer, S., Berntsen, T., Berglen, T., Boucher, O., Chin, M., Dentener, F., Diehl, T., Easter, R., Feichter, H., Fillmore, D., Ghan, S., Ginoux, P., Gong, S., Grini, A., Hendricks, J., Horowitz, L., Huang, P., Isaksen, I., Iversen, I., Kloster, S., Koch, D., Kirkevåg, A., Kristjansson, J. E., Krol, M., Lauer, A., Lamarque, J. F., Liu, X., Montanaro, V., Myhre, G., Penner, J., Pitari, G., Reddy, S., Seland, Ø., Stier, P., Takemura, T., and Tie, X.: Analysis and quantification of the diversities of aerosol life cycles within AeroCom, Atmos. Chem. Phys., 6, 1777-1813, 2006, http://www.atmos-chem-phys.net/6/1777/2006/.

Timmermans, J.: The Physico-chemical constants of binary systems in concentrated solutions, Vol. 4, Interscience Publishers, New York, 1960.

Topping, D. O., McFiggans, G. B., Kiss, G., Varga, Z., Facchini, M. C., Decesari, S., and Mircea, M.: Surface tensions of multicomponent mixed inorganic/organic aqueous systems of atmospheric significance: measurements, model predictions and importance for cloud activation predictions, Atmos. Chem. Phys., 7, 2371-2398, 2007, http://www.atmos-chem-phys.net/7/2371/2007/.

Vanhanen, J., Hyvärinen, A.-P., Anttila, T., Raatikainen, T., Viisanen, Y., and Lihavainen, H.: Ternary solution of sodium chloride, succinic acid and water; surface tension and its influence on cloud droplet activation, Atmos. Chem. Phys., 8, 4595-4604, 2008 , http://www.atmos-chem-phys.net/8/4595/2008/.

Varga, Z., Kiss, G., and Hansson, H.-C.: Modelling the cloud condensation nucleus activity of organic acids on the basis of surface tension and osmolality measurements, Atmos. Chem. Phys., 7, 4601-4611, 2007, http://www.atmos-chem-phys.net/7/4601/2007/.

Wex, H., Kiselev, A., Stratmann, F., Zoboki, J., and Brechtel, F.: Measured and modeled equilibrium sizes of $\mathrm{NaCl}$ and $\left(\mathrm{NH}_{4}\right)_{2} \mathrm{SO}_{4}$ particles at relative humidities up to $99.1 \%$, J. Geophys. Res.-Atmos., 110, 1-9, doi:10.1029/2004JD005507, 2005.

Wex, H., Hennig, T., Salma, I., Ocskay, R., Kiselev, A., Henning, S., Massling, A., Wiedensohler, A., and Stratmann, F.: Hygroscopic growth and measured and modeled critical super-saturations of an atmospheric HULIS sample, Geophys. Res. Lett., 34, 1-5, doi:10.1029/2006GL028260, 2007. 
Wex, H., Stratmann, F., Topping, D. and McFiggans, G.: The Kelvin versus the Raoult term in the Köhler equation, J. Atmos. Sci., 65, 4004-4016, doi:4010.1175/2008JAS2720.4001, 2008.

Wex, H., Petters, M. D., Carrico, C. M., Hallbauer, E., Massling, A., McMeeking, G. R., Poulain, L., Wu, Z., Kreidenweis, S. M., and Stratmann, F.: Towards closing the gap between hygroscopic growth and activation for secondary organic aerosol: Part 1 - Evidence from measurements, Atmos. Chem. Phys., 9, 3987-3997, 2009 ,

http://www.atmos-chem-phys.net/9/3987/2009/.

Widera, B., Neueder, R., and Kunz, W.: Vapor pressures and osmotic coefficients of aqueous solutions of SDS, C(6)TAB, and C(8)TAB at 25 degrees C, Langmuir, 19, 8226-8229, doi: 10.1021/la034714, 2003.
Zelenyuk, A., Cai, Y., and Imre, D.: From agglomerates of spheres to irregularly shaped particles: Determination of dynamic shape factors from measurements of mobility and vacuum aerodynamic diameters, Aerosol Sci. Tech., 40, 197-217, doi:10.1080/ $02786820500529406,2006$.

Ziese, M., Wex, H., Nilsson, E., Salma, I., Ocskay, R., Hennig, T., Massling, A., and Stratmann, F.: Hygroscopic growth and activation of HULIS particles: experimental data and a new iterative parameterization scheme for complex aerosol particles, Atmos. Chem. Phys., 8, 1855-1866, 2008,

http://www.atmos-chem-phys.net/8/1855/2008/. 